\title{
Myelodysplastic Syndrome and Histone Deacetylase Inhibitors: “To Be or Not to Be Acetylated"?
}

\author{
Sebastian Stintzing, ${ }^{1}$ Ralf Kemmerling, ${ }^{2}$ Tobias Kiesslich, ${ }^{3}$ Beate Alinger, ${ }^{2}$ \\ Matthias Ocker, ${ }^{4}$ and Daniel Neureiter ${ }^{2}$ \\ ${ }^{1}$ Medical Department III, Klinikum Grosshadern, Ludwig Maximilians University of Munich, Marchioninistraße 15, \\ 81377 Munich, Germany \\ ${ }^{2}$ Institute of Pathology, Paracelsus Medical University/Salzburger Landeskliniken (SALK), Müllner Hauptstrasse 48, \\ 5020 Salzburg, Austria \\ ${ }^{3}$ Department of Internal Medicine I, Paracelsus Medical University/Salzburger Landeskliniken (SALK), Müllner Hauptstrasse 48, \\ 5020 Salzburg, Austria \\ ${ }^{4}$ Philipps University of Marburg, Baldingerstrasse, 35032 Marburg, Germany
}

Correspondence should be addressed to Daniel Neureiter, d.neureiter@salk.at

Received 13 July 2010; Accepted 3 March 2011

Academic Editor: Patrick Matthias

Copyright (C) 2011 Sebastian Stintzing et al. This is an open access article distributed under the Creative Commons Attribution License, which permits unrestricted use, distribution, and reproduction in any medium, provided the original work is properly cited.

Myelodysplastic syndrome (MDS) represents a heterogeneous group of diseases with clonal proliferation, bone marrow failure and increasing risk of transformation into an acute myeloid leukaemia. Structured guidelines are developed for selective therapy based on prognostic subgroups, age, and performance status. Although many driving forces of disease phenotype and biology are described, the complete and possibly interacting pathogenetic pathways still remain unclear. Epigenetic investigations of cancer and haematologic diseases like MDS give new insights into the pathogenesis of this complex disease. Modifications of DNA or histones via methylation or acetylation lead to gene silencing and altered physiology relevant for MDS. First clinical trials give evidence that patients with MDS could benefit from epigenetic treatment with, for example, DNA methyl transferase inhibitors (DNMTi) or histone deacetylase inhibitors (HDACi). Nevertheless, many issues of HDACi remain incompletely understood and pose clinical and translational challenges. In this paper, major aspects of MDS, MDS-associated epigenetics and the potential use of HDACi are discussed.

\section{Introduction}

Myelodysplastic syndromes (MDS) represent a heterogeneous spectrum of haematopoietic disorders ranging from ineffective haematopoiesis with cytopenia to progressive haematopoiesis with transition to acute myeloid leukaemia showing morphological and functional abnormalities of haematopoietic cells [1-3].

Due to difficulties in diagnosis and classification, epidemiological analyses report different incidence rates [4]. Nevertheless, it has been observed that intensive cancer therapeutic regimes lead to higher incidence rates of secondary forms of MDS [5]. As reviewed by Corey et al. [6] and Bernasconi [7], pathogenetic concepts favoured (i) chromosomal alterations and (ii) gain- and loss-of-function of protooncogenes and suppressor genes as well as (iii) disturbance of mitochondrial energy pathway and associated apoptosis. Although good progress was done to develop well-defined step-by-step pathogenetic models such as in colorectal cancer [8-11], the heterogeneous morphological spectrum and different clinical course of MDS remains poorly understood. Therefore, different subgroups of MDS with their characteristic cytogenetic, molecular, and immunological abnormalities were defined by international prognostic scoring systems such as the FAB (French American British) and the WHO classification to help to adequately stratify therapeutic regimens $[1,3,12]$. As described, the primary goal of treatment is haematological improvement in cases with 
low-risk MDS and targeting the underlying disease in cases with high-risk MDS [13]. Recently, experimental and clinical investigations revealed that epigenetic processes could play a key role in MDS and could be innovative targets for therapeutic approaches [14-18].

We therefore want to give a comprehensive survey of MDS in the frame of epigenetics with focuses on clinical, pathogenic, and therapeutic issues.

\section{A Survey of Myelodysplastic Syndrome (MDS)}

2.1. A Short Introduction to the Definition, Classification (with Prognostic Groups), Epidemiology, and Aetiology. According to the WHO, the myelodysplastic syndrome (MDS) is defined as a heterogeneous disease group with cytopenia due to ineffective haematopoiesis and with dysplastic morphological changes in one or more of the myeloid cell lineages and associated risk to progression into acute myeloid leukaemia [1-3].

Based on "characteristic" dysplastic features of haematopoietic cells (in the bone marrow as well as in the peripheral blood) [19-21] five "specific" subgroups of the MDS were distinguished $[1,22]$, which could be more sophistically subclassified by integrating specific cytogenetic investigations such as MDS with deletion of chromosome $5 \mathrm{q}$ done by the WHO in 2008 (as reviewed in detail [2, 3, 22]). Established MDS prognostic groups of low, intermediate I and II as well as of high risk (like the international prognostic scoring system (IPSS)) could identify the individual life risk and could be helpful for therapeutic decisions implementing blast count (according to the WHO classification), the number of cytopenias and cytogenetic findings [12] as well as parameter of red blood cell transfusion [23]. Interestingly, molecular alterations that are linked to specific signalling pathways of MDS like signalling and differentiation, cell cycle regulations, apoptosis, and translation are not integrated into the existing scoring system until now reflecting the morphological and molecular heterogeneity of this haematological entity $[13,22$, 23].

MDS could be observed primarily de novo or after radiation or chemotherapy (especially in patients treated with alkylating agents or topoisomerase II inhibitors) as so-called secondary or therapy-associated form of MDS [5, 24-27]. Epidemiological data indicate that especially primary forms of MDS increase with the age of patients [28]: several authors reported an overall incidence rate of MDS ranging between 3.5 to 12.6 per 100,000 population per annum [29-31]. Ageing of the population in the Western world [32-34] and the extensive use of chemo- and radiotherapy for the treatment of malignant tumours [4, 24, 28, 35] will increase the incidence of MDS. Therefore, MDS becomes an important sociomedical issue, as epidemiological investigations revealed an age-specific increase of incidence between the age group of below 70 and above 70 years from 4.9 to 22.8 [36], 1.6 to 15.0 [30], or 15.0 to 49.0 [31], comparable to our own investigations [35].

As discussed above, the linkage between chemotherapy/radiotherapy and therapy-associated MDS is well known.
Yet, knowledge about the aetiology of the large majority of de novo MDS is not fully conclusive, since some of the postulated risk factors for MDS (such as hair dyes, alcohol, and viral disease) showed only a weak or no association with MDS compared to accepted risk factors like solvents, cigarette smoking, and radiation $[4,37]$. The inheritance of susceptibility genes is still unclear. Two commonly deleted segments, $5 \mathrm{q} 31$ and $7 \mathrm{q} 22$, were identified by cytogenetic analysis, which contains tumour-suppressor genes, and are therefore critical regions to MDS development, which could be inherited (germline) or induced by antitumour-therapy (somatic) as reviewed in $[38,39]$. Finally, a small percentage of MDS in adults and in children is associated with genetic disorders such as Fanconi anaemia, Bloom syndrome, Diamond-Blackfan syndrome as well as Down syndrome, Shwachman-Diamond syndrome, and neurofibromatosis [6].

2.2. Pathogenetic Insights. As reviewed in detail by Corey et al. [6], Bernasconi [7] and Nimer [18] common and distinct pathways are involved in the pathogenesis of MDS, which could be summarized by (i) chromosomal/genetic alterations and molecular defects, (ii) disturbance of the microenvironment, and (iii) deregulation of apoptosis as discussed in detail below (see also Figure 1).

2.2.1. The Stem Cell Genetic Defect. Cytogenetic investigations revealed a broad range of defects which are linked to specific biological, clinical, and therapeutic features of MDS as reviewed in detail elsewhere [7]. Overall, chromosomal abnormalities could be detected in about $40-60 \%$ of primary and in about $70-90 \%$ of secondary forms of MDS ranging from balanced/unbalanced chromosomal rearrangements to specific chromosomal abnormalities such as $\operatorname{Del}(5 q),-7$, $\operatorname{Del}(7 \mathrm{q}),+8, \operatorname{Del}(20 \mathrm{q}),-\mathrm{Y}, 17 \mathrm{p}$ rearrangements, 11q23 translocations as well as complex karyotypes ( $\geq 3$ defects) [7, 10,39 ]. Compared to AML, more deletions and numerical defects than translocations were observed in MDS, which go along with nonclonal defects indicating a different pathogenesis in MDS compared to AML [40, 41]. The role of these chromosomal abnormalities for MDS still remains unclear, since "typical" class I and II mutations in the leukemic transformation of AML are missing in MDS [7, 10,39 ], normal and abnormal karyotypes are observed sideby-side in bone marrow of patients with MDS and, finally, chromosomal aberrations are found more often in late than early stages of MDS [42].

Looking on molecular defects in MDS, multiple genes are affected such as CDKN2B, EVI1, IRF1, NRAS, TP53, FLT3, and MLL (in decreasing incidence according to [10]) by mutations, deletions, ectopic expression, or promoter methylation which could influence the expression of tumour suppressor genes, if genetic or epigenetic alterations of the other allele occurred as postulated by Knudson's hypothesis [43].

Based on the knowledge that the described genetic defect in MDS could be both somatic and/or germline-associated [44-46], the genetic heterogeneity of MDS demand for 


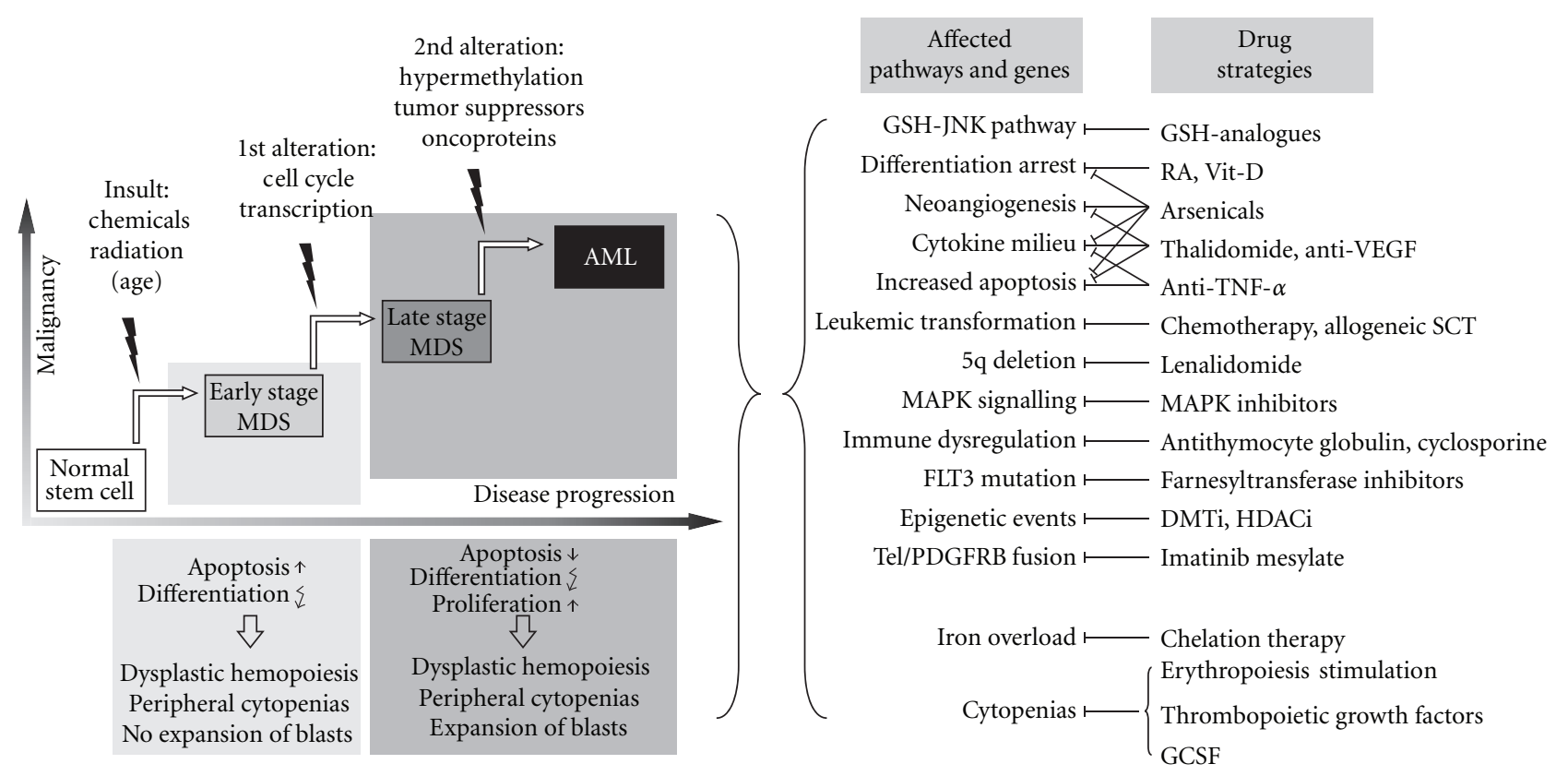

FIGURE 1: Pathophysiological mechanisms involved in MDS and points of action for possible therapy approaches. Abbreviations: AML: acute myeloid leukaemia; GCSF: granulocyte colony-stimulating factor; GSH: glutathione; MAPK: mitogen-activated protein kinase; MDS: myelodysplastic syndrome; PDGFR: platelet-derived growth factor receptor; RA: retinoic acid; SCT: stem cell transplantation; TNF: tumour necrosis factor; VEGF: vascular-endothelial growth factor.

cytogenetic analysis in each individual case to evaluate the risk of heredity and of disease-progression as well as to develop better therapeutic options [47].

2.2.2. The Role of the Microenvironment. It was shown that abnormalities of the bone marrow microenvironment play a role in the pathogenesis of MDS by abnormal expression levels of cytokines such as interleukin $1 \beta$, interleukin 6, and tumour necrosis factor (TNF)- $\alpha[48,49]$. In detail, there is evidence that an enhanced TNF- $\alpha$ expression induced resistance of MDS cells to the proapoptotic effects of TNF- $\alpha$ leading to proliferation and progression [50]. Additionally, deregulation of proangiogenesis factors (like vascular endothelial growth factor (VEGF)) promotes an enhanced self-renewal and cytokine elaboration [51]. In contrast to the findings on VEGF, the expression of matrix metalloproteinases (MMP) (especially MMP2 and MMP9) in monocytes correlated with an increased apoptotic rate and longer overall survival in MDS patients [52].

2.2.3. Apoptosis Deregulation. Deregulation of apoptotic processes is mainly observed in early stages of MDS, whereas a deregulation of proliferation is found in advanced MDS. This is supported by the investigation of apoptosisassociated markers (ligands and receptors) as reviewed by Bernasconi [7]. In low-risk MDS, an upregulation of Apo 2.7, TRAIL, FAS/CD95, p38, TNFR1, CFLARs and Erk1/2 and downregulation of bcl-2, TNFR2, CFLAR $\mathrm{L}_{\mathrm{L}}$ NF- $\kappa \mathrm{B}$, and AKT were found, whereas in high-risk MDS a diametric expression pattern was observed. Apoptosis can be influenced differentially by cytogenetic defects and by cytokine disarrangement of the stromal cell compartments. For instance, MDS associated with aneuplodies (such as three copies of chromosome 8) presents a significantly higher percentage of apoptotic CD34+ cells. Furthermore, MDS cells with isolated deletion of chromosome $5 \mathrm{q}$ showed a $\mathrm{G}_{0} / \mathrm{G}_{1}$ arrest through the antiproliferative effect of lenalidomide by the adjustment of growth and differentiation signals inside the bone marrow environment [41]. Finally, extrinsic apoptotic pathways could be deregulated by uncontrolled upregulation of apoptosis-associated proteins like FAS/CD95, TNF $\alpha$, or TRAIL ligands [53].

2.2.4. Molecular Signals for MDS Progression towards AML. What are the essential molecular signals promoting MDS towards AML? Experimental findings investigating apoptotic deregulation suggest a continuous switch from predominant proapoptotic to a more proproliferative status of MDS cells $[6,7]$. Transcriptional pathways essentially involved in this process are the RELA/NFKB1 and the PI3KC2A/AKT1 signal transduction axis $[54,55]$. In short, proinflammatory cytokines (such as TNF $\alpha$, TRAIL, and FAS/CD95) activate the CHUK/IKBKB complex with consecutive release and nuclear translocation of RELA and NFKB1 along with activation of genes being associated with cell growth, differentiation, inflammation, and apoptosis [7].

In summary, our knowledge of (i) these specific molecular abnormalities in the haematopoietic cells in MDS as well as of (ii) immune deregulation and of (iii) abnormal bone marrow environment in MDS is sophisticated [8-11] (see also Figure 1) and could not explain the heterogeneous 
morphological and clinical presentation of this complex disease. Additionally, mouse models of MDS currently available are not suited to reflect all of the features of MDS [5658]. Taken together, the differentiation as well as proliferation/survival is impaired in MDS with potency to progression to AML due to an unknown second hit event [18].

2.3. Therapeutic Approaches. Standardised therapeutic stratifications were established depending on the prognostic subgroups and with respect to age and performance status of the patients (see also Table 1). The therapeutic aims are: (i) a haematological improvement in low-risk and (ii) altering natural disease course in high-risk MDS disease subgroups. Additional information on clinical and molecular features (as mentioned above) will lead to a tailored, individualised decision management for therapy in future (see Figure 1).

Until now, internationally approved drugs to treat patients with MDS are erythropoietin, darbepoeitin, lenograstim (G-CSF), 5-azacytidine, decitabine, anti-thymocyte globulin, cyclosporine, lenalidomide, deferasirox, and deferoxamine [13].

In short, the mechanistic aspects of these currently available treatment options are explained.

(i) In the "best supportive care" setting erythropoietin, darbepoeitin and lenograstim (G-CSF) act as classical hematopoietic growth factors stimulating normal residual hematopoiesis, whereby additional effects of these drugs such as inducing differentiation of dysplastic hematopoiesis via blocking of apoptosis are discussed $[61,62]$.

(ii) The chelation therapy with deferasirox and deferoxamine has the intention to reduce the transfusional iron overload associated with organ dysfunction due to chronic anaemia in MDS by mobilization of organ iron deposit and increased secretion of urinary iron $[63,64]$.

(iii) Anti-thymocyte globulin, cyclosporine, and lenalidomide have similar immune modulatory properties interacting with deregulated lymphocytes (such as $\mathrm{CD} 4 / \mathrm{CD} 8$ ratio or $\mathrm{T}$-cell receptor repertoire) observed in MDS. Additionally, anti-thymocyte globulin and lenalidomide target changes in bone marrow microenvironment in MDS through antiangiogenic and antiproliferative capacities via modifying integrin and chemokine networks. Especially, lenalidomide has the property for direct clonal suppression of myelodysplastic clones with isolated deletion of chromosome 5q [40, 41, 65, 66].

(iv) The transcriptional modifying therapy contains the two hypomethylating agents 5-azacytidine and decitabine. These two drugs are analogues of the pyramidine nucleoside cytidine and are integrated into RNA (5-azacytidine) or DNA (both), inducing progressive loss of methylation by covalently binding to DNA methyltransferases which are critical components of the epigenetic network inside normal and uncontrolled proliferation and differentiation $[15,67]$.

This heterogeneous list of drugs mirrors the different pharmacological approaches according to the stages and pathomechanisms of MDS. The development of new standardised guidelines for treatment of MDS as done by the National Comprehensive Cancer Network (NCCC) is therefore urgently needed (to view the most recent and complete version of the guidelines, see also http://www.nccn.org/) integrating ongoing response findings of clinical trials (e.g. based on epigenetic approaches $[14,16,18,68])$.

2.3.1. Lower Risk MDS. According to the NCCC practical guidelines for patients with low-risk MDS, a supportive care for symptomatic anaemia and thrombocytopenia is mandatory to additional therapy depending on detectable genetic abnormalities. In cases of $\operatorname{del}(5 q)$ and other cytogenetic abnormalities, treatment with lenalidomide is indicated. In case of no response and all other remaining cases, the decision of treatment with azacytidine, decitabine, antithymocytes globulin, cyclosporine, or again lenalidomide depends on the serum erythropoietin levels $(<>500 \mathrm{mU} / \mathrm{mL})$ as described in detail on the NCCC homepage. Additionally, the iron overload should be reduced by the use of iron chelators to reduce the risk of cardiac dysfunction.

2.3.2. Higher Risk MDS. According to the NCCC practical guidelines for patients with high-risk MDS, the intensity of treatment depends on the performance status of the patient and eligibility for allogenic haematopoietic stem cell transplantation (HSTT). Since the majority of patients with highrisk MDS are relatively old $(>70 \mathrm{yr})$, most of these patients are not possible candidate for high intensity induction chemotherapy and consecutive allogeneic HSTT and therefore receive azacytidine (preferred)/decitabine. The experience with allogeneic HSTT are disillusioning, since the response rate of allogeneic HSTT is generally low in comparison to de novo AML $[69,70]$. Newer decision pathways for allogeneic HSTT as well as new induction regimes (such as reduced intensity conditioning) are in development to improve this high-intensity therapy [13].

Additionally, new therapies with heterogeneous pharmacological approaches for MDS are currently developed and investigated in ongoing clinical trials targeting selective pathways within the pathogenesis of MDS showing encouraging results and offering durable benefit to patients with MDS. These new drugs could be sorted according the targeted mechanism $[68,71,72]$ : (i) interaction with survival signals such as antiangiogenesis, receptor tyrosine kinase inhibitors, protein kinase $\mathrm{C}$ inhibitors, matrix metalloprotease inhibitors, and farnesyl transferase inhibitors and (ii) interaction with genetic integrity such as immunoconjugate and P-glycoprotein antagonists.

Additionally, an alternative, potential, and promising approach could consist in the application of agents affecting epigenetic pathomechanisms, including histone deacetylase inhibitors (HDACi) such as vorinostat (SAHA), valproic acid, entinostat (MS275/SDX275), or panobinostat 
TABLE 1: Therapeutic strategies in MDS depending of risk stratifying (adapted from $[59,60]$ ).

\begin{tabular}{lcc}
\hline & Low-risk MDS & High-risk MDS \\
\hline $\begin{array}{l}\text { Survival } \\
\text { Risk of AML transformation }\end{array}$ & $3-10$ years & $<1.5$ years \\
WHO entities & Low rate & High rate \\
IPSS Score (see [12]) & RA, RARS, RCUD, RCMD, MDS-U, MDS & RAEB $(-1,-2)$ \\
& Low, Int-1 (score $0-1.0)$ & Int-2, high (score $\geq 1.5)$ \\
& Growth factors: Erythropoietin, G-CSF & Decitabine, 5-azacitidine \\
Immune therapy: steroids, cyclosporin, & Investigational \\
approved and applied drugs/therapies & Lenalidomide: $5 \mathrm{q} 31$ & Intensive chemotherapy \\
& Decitabine, 5-azacitidine & (Younger, karyotype diploid), allogeneic \\
stem cell transplantation & Iron chelation \\
Future therapeutic perspectives & Iron chelation & Translocation $(5 ; 12)$ or 5q23 \\
variant (PDGFR-B): Imatinib
\end{tabular}

Abbrevations. AML: acute myeloid leukaemia; G-CSF: granulocyte-colony-stimulating factor; IPSS: International Prognostic Scoring System; MDS-U: MDS unclassifiable; MDS del(5q): MDS associated with isolated deletion of chromosome 5q; PDGFR-B: platelet-derived growth factor receptor B; RA: refractory anemia; RAEB: RA with excess blasts; RARS: RA with ring sideroblasts; RCMD: refractory cytopenia with multilineage dysplasia; RCUD: refractory cytopenia with unilinease dysplasia.

(LBH589). This class of agents (as discussed in detail below) are very interesting in the treatment of MDS, since HDACis reveal pleiotropic effects on cell cycle, differentiation, and apoptosis $[73,74]$ which are linked and deregulated in MDS.

\section{Cancer, Epigenetics, and HDACi}

3.1. Cancer and Epigenetic: A Short Overview. Carcinogenesis is characterised by different sequential or parallel genetic/epigenetic hits with a gain- and/or a loss-of-function that leads to "hallmarks of cancer" such as proliferation, apoptosis, tissue remodelling, metastasis, and neoangiogenesis, as described in detail by Hanahan and Weinberg in an outstanding review [75]. In recent years, the importance of epigenetic alterations in carcinogenesis processes is emphasised and lead to the development of novel therapeutic approaches.

At a glance, epigenetic mechanisms include DNA methylation of cytosine residues inside $\mathrm{CpG}$ islands often found within transcriptional promoter regions in the DNA and various histone modifications leading to altered gene expression [76-78] (see also Figure 2).

3.2. The Role of Histone Modifications. Basic histone proteins $\mathrm{H} 2 \mathrm{a}, \mathrm{H} 2 \mathrm{~b}, \mathrm{H} 3$, and $\mathrm{H} 4$ build an octamer, called nucleosome packing the DNA by coiling into the nucleus [79]. These histone complexes are posttranslationally modified by different levels of methylation, acetylation, phosphorylation, or ubiquitinylation in order to coordinate the regulation of gene transcription-a process referred to as "histone coding" [80]. These acyl modifications of histone proteins are exerted by two groups of highly conserved enzymes called histone acetyl transferases (HAT) and histone deacetylases (HDAC). HAT transfer acetyl groups to $\varepsilon$-amino groups of lysine residues in all four histone proteins leading to an "open" conformation of chromatin allowing subsequent binding of transcription factors, whereas the typical result of deacetylation by HDACs is condensed chromatin associated with transcriptional repression [81]. Interestingly, only 2 to 10 percent of all genes are regulated by this mechanism as demonstrated using gene arrays emphasizing the role of this "histone code" [74, 82, 83]. However, this data displayed the change in global gene expression, and these studies did not investigate single histone acetylation status or functional analysis of histone deacetylation.

Until now more than 30 different HATs have been described and have been divided into two main classes with different cellular distribution. Whereas A-type HATs are found in the nucleus and have a transcriptional role, B-type HATs are located in the cytoplasma $[84,85]$. On the other side, at least 18 different HDACs have been published and are categorised into four major groups based on their sequence homology to their respective yeast HDACs $[73,86]$ : Class IHDACs (Rpd3-like) with the zinc-dependent isotypes HDAC $1,2,3$, and 8 are located in the nucleus and act as transcriptional corepressors. Class II-HDACs (Had1-like) with HDAC 4, 5, 6, 7, 9, and 10 are located in nucleus and cytoplasma and show also a transcriptional corepressor function but also mediate a variety of cytoplasmic nonhistone protein modifications [87]. Class III-HDACs (sirtuins) with SIRT1 to 7 are associated with regulation of cell proliferation and cell cycle control. Additionally, HDAC11 represents a separate class (class IV) of HDACs, since HDAC11 is structurally related to both, class I and II HDACs [88].

This subtype of epigenetic mechanisms of histone modification is centrally involved in the regulation of differentiation, proliferation, and tissue maintenance during embryogenesis $[89,90]$. In contrast, deregulated epigenetic action of HDACs is observed in various types of human tumours 


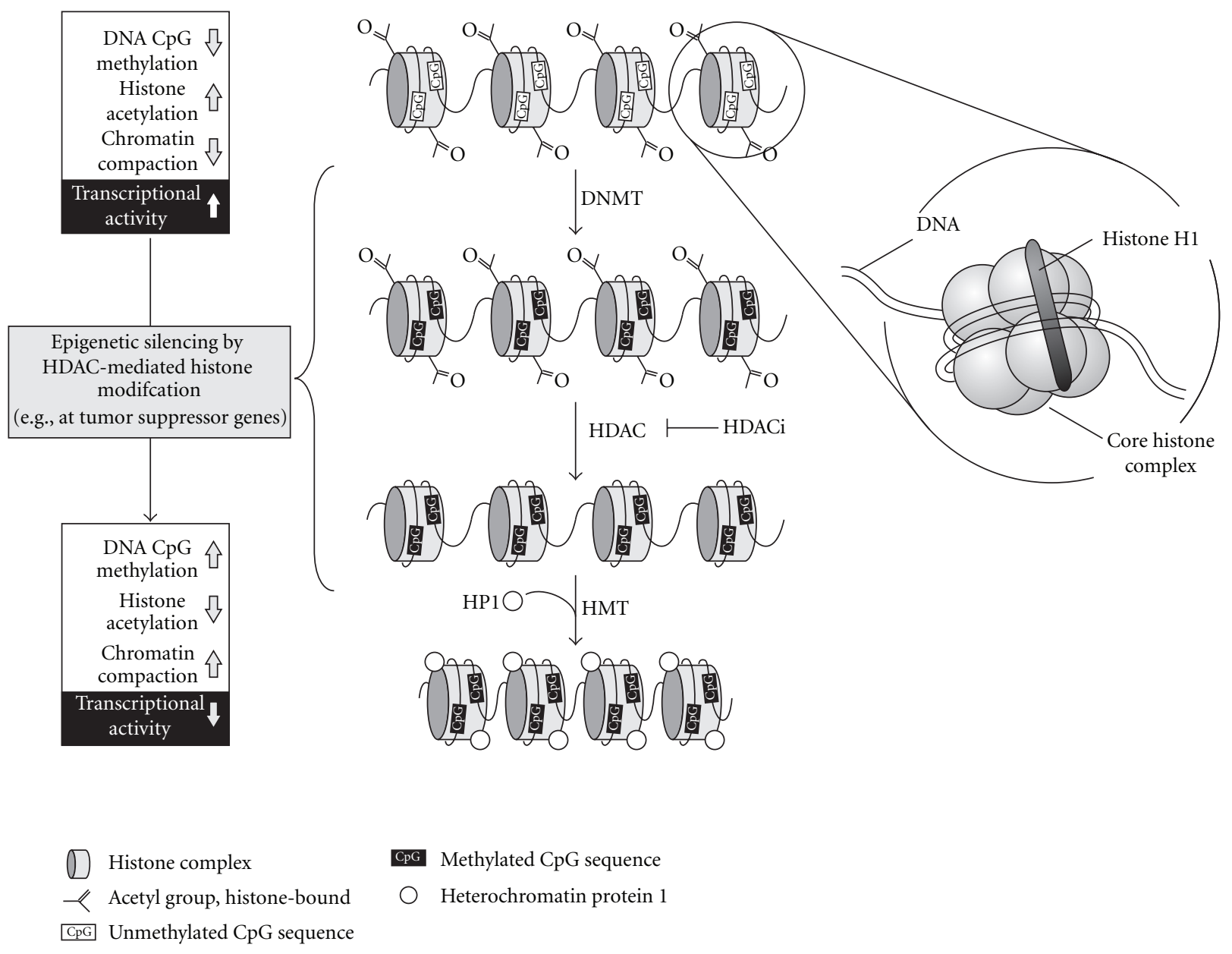

FIGURE 2: Overview of transcriptional regulation by epigenetic mechanisms involving DNA methylation and histone acetylation. Abbreviations: DNMT: DNA methyl transferase; HDAC(i): histone deacetylase (inhibitor); HMT: histone methyltransferase; HP1: heterochromatin protein 1.

such as gastric (HDAC1), breast (HDAC1, HDAC6), or colon carcinoma (HDAC3) [91-94]. Additionally, histone modifications are essentially involved in haematological diseases such as leukaemias as reviewed by Issa [16]. For that reason, the inhibition of HDACs generally seems to be a promising and novel approach in the treatment of human cancer.

3.3. Molecular Classes and Mechanisms of HDACi. Many chemical substances have been developed to inhibit HDACs in vitro and in vivo which could be divided in hydroxamic acid derivates, cyclic tretapeptides, benzamides, and shortchain fatty acids as listed in Table 2 . Some of them are tested in clinical trials $[81,95]$, whereas until now only superoylanilide hydroxamic acid (SAHA) has received approval by the FDA for the treatment of cutaneous T-cell lymphoma [96].

In general, the effects of such HDACi are pleiotropic with induction of differentiation, growth arrest, and/or apoptosis of tumour cells [97, 98]. To evaluate the possible role of HDACi in MDS, it is necessary to look into the molecular mechanism of HDAC inhibition. Although the exact mechanisms of anticancer effect by HDACi are under debate, HDACi have both specific and unspecific effects $[74,81,99]$. With the exception of HDAC6 inhibitors, all HDACi induce a $G_{1} / S$-phase cell cycle arrest associated with an increased expression of the endogenous cyclin-dependent kinase inhibitor $\mathrm{p} 21^{\text {cip1/wafl }}[100,101]$. This action can be both p53-dependent and -independent as shown by our own experiments $[102,103]$. For all other effects observed for HDACi such as upregulation of the death receptor pathway (extrinsic (TRAIL-mediated) and intrinsic (mitochondrialrelated)), induction of reactive oxygen species, and alteration of chaperone function (part of the cellular stress response) or NF- $\kappa$ B pathway (modulator of the inflammatory pathway), it is difficult to define if the effects of HDACi are directly triggered by transcriptional regulation that is mediated by hyperacetylation [87, 104]. Newer investigations revealed that acetylation and deacetylation represent an ubiquitous regulation mechanism for cellular networking such as RNA splicing, DNA damage repair, cell cycle control, nuclear transport, actin remodelling, ribosome, and chaperone function that is summarised as "acetylome" [105-108]. Additionally, HDACis influence posttranscriptional pre-mRNA 
TABLE 2: Selected HDAC inhibitors: structural class, compound, isotype selectivity, and study phase—an overview (according to Batty et al. [14] and Schneider-Stock and Ocker [81]).

\begin{tabular}{|c|c|c|c|}
\hline Structural & HDAC inhibitor (synonyms, abbreviation, supplier) & Class selectivity & Study phase \\
\hline \multirow{8}{*}{ Hydroxamic acids } & m-carboxycinnamic acid bis-hydroxamide (CBHA) & & \\
\hline & Oxamflatin & & \\
\hline & Belinostat (PXD-101, Curagen Corp/TopoTarget A/S) & I, IIa, IIb, IV & II \\
\hline & Pyroxamide & & I \\
\hline & Scriptaid & & \\
\hline & Superoylamilide hydroxamic acid (SAHA, Vorinostat) & I, IIa, IIb, IV & FDA approval (CTCL) \\
\hline & Trichostatin A (TSA) & I, II & \\
\hline & Panobinostat (LBH-589; Novartis AG) & I, IIa, IIb, IV & II \\
\hline \multirow{4}{*}{ Cyclic tretapeptides } & Apicidin & I, II & \\
\hline & Romidepsin (FK-228, FR-901228; Gloucester Pharmaceuticals Inc) & I, II & II \\
\hline & Trapoxin-histone acetylase (TPX-HA) analog (CHAP) & & \\
\hline & Trapoxin & & \\
\hline \multirow{2}{*}{ Benzamides } & Tacedinaline (CI-994; Pfizer Inc) & & \\
\hline & Entinostat SNDX-275 (MS-275; Syndax Pharmaceuticals Inc) & I, II & II \\
\hline \multirow{2}{*}{ Short-chain fatty acids } & Butyrate & I, IIa & $\mathrm{I}$ \\
\hline & Valproic acid & I, IIa & $\mathrm{I}$ \\
\hline
\end{tabular}

processing and proteasomal and nonproteosomal pathways with heterogenous and different effect on ubiquitination [109], so that it is impossible to define a general mode of action for HDACi [87].

3.4. Clinical Application and Experience of HDACi. The majority of chemically designed HDACi is under intensive clinical investigation for treatment of haematological diseases such as acute or chronic leukaemias, lymphomas, and MDS $[110,111]$. Currently, only the pan-deacetylase inhibitor SAHA has been approved by the FDA for treatment of cutaneous T-cell lymphoma (CTCL) [96]. Until now, the overall response reached up to $30 \%$, but long-term surveillance is still missing. From a pharmacokinetic view most of HDACi used in clinical phase I studies have short half-life in plasma (2-8 hrs, except for MS-275 with $80 \mathrm{~h} \mathrm{[112]),} \mathrm{followed} \mathrm{by}$ hepatic metabolism and intestinal excretion [113-118]. The major adverse toxicities of HDACi include fatigue, somnolence, confusion, diarrhoea, myelosuppression, and QT prolongation, thus limiting therapeutic applications [113118]. Additionally, two questions regarding the use of HDACi are still unanswered. (i) It is currently unclear whether more specific HDAC class I \& II inhibitors (like MS-275) or pan-deacetylase inhibitors (like SAHA or panobinostat) are more efficient in tumour reduction. (ii) Furthermore, is the acetylation of histone $\mathrm{H} 3$ in peripheral blood mononuclear cells a tool for biomarker HDAC inhibitor efficiency [113]? Various studies could not confirm a correlation of peripheral $\mathrm{H} 3$ acetylation and tumour treatment responses $[110,111]$. Acetylation of peripheral $\mathrm{H} 3$ as well as expression of p21 in peripheral blood cells have been considered as potential biomarkers but were shown to possess only a poor correlation with the cognate expression pattern inside a (solid) tumour and with the overall response to the treatment. Additionally, an assay of HDAC enzymatic activity in intact cells on the basis of a cell-permeate substrate with fluorescent read-out was evaluated in two phase I trials, whereby the reliability of this test is not clear $[116,119]$. For that, adequate biomarkers for monitoring tumour target effects of HDACi are still missing.

\section{MDS, Epigenetics, and HDACi}

It is still under debate how much epigenetics influences initiation and the clinical course of MDS. As mentioned above, experimental data suggest that especially DNA methylation plays an important role in the disrupted haematopoeisis [16]. In the progression of MDS, associated tumour suppressor genes are increasingly methylated, leading to resistance to classical cytotoxic chemotherapy [67]. For instance, methylation frequency of the tumour suppressor genes $\mathrm{p} 15, \mathrm{CDH}-1, \mathrm{DAP}-\mathrm{Kinases}$, and SOCS-1 was detected in $89 \%, 48 \%, 28 \%$, and $62 \%$ of patients with MDS, chronic myelomonocytic leukaemia, and high-risk AML, respectively [120]. Additionally, a genomics-based methylation assay of CD34+ cells of normal control patients and patients with MDS or AML revealed that more than 700 unique genes in CD34+ cells of MDS patients showed hypermethylation compared to normal controls $[121,122]$. Recently, mutations of polycomb-associated gene ASXL1 which regulates histone modifications is described in MDS and chronic myelomonocytic leukaemia [123]. Nevertheless, "hard" data on the acetylation status in MDS are missing or are particularly published in circumstance of clinical trials of HDACi or in combination with DNA methyl transferase inhibitors (DNMTi), described below in detail.

4.1. Clinical Trials Phase I/II. In 2001, the HDAC inhibitor valproic acid (VA) in combination with all-trans retinoic acid (ATRA) was shown to induce differentiation in malignant 
TABLE 3: Clinical trials of HDACi in MDS and AML (adapted and extended from [15, 17]; see also current and ongoing clinical trials at http://www.clinicaltrials.gov/).

\begin{tabular}{|c|c|c|c|c|c|c|c|}
\hline Author (year) & HDACi substance & Phase & Schedule & $\begin{array}{l}\text { Patient } \\
\text { number }\end{array}$ & $\begin{array}{c}\text { Diagnosis: patient } \\
\text { number }\end{array}$ & $\begin{array}{l}\text { Responses } \\
\text { (i) overall [\%] } \\
\text { (ii) details }\end{array}$ & Toxicity \\
\hline $\begin{array}{l}\text { Gore et al. } \\
\text { (2001) [127] }\end{array}$ & Phenylbutyrate & I & $\begin{array}{c}\text { i.v., } \\
125-500 \mathrm{mg} / \mathrm{kg} / \text { day } \\
7 / 28 \text { days } \\
\text { continuous infusion }\end{array}$ & 27 & $\begin{array}{l}\text { MDS: } n=11, \\
\text { AML: } n=16\end{array}$ & $\begin{array}{c}8[30 \%] \\
4 \mathrm{HI}, 4 \text { decline of } \\
\text { PB blasts }\end{array}$ & $\begin{array}{l}\text { CNS toxicity, } \\
\text { hypocalcemia, } \\
\text { nausea/vomiting }\end{array}$ \\
\hline $\begin{array}{l}\text { Gore et al. } \\
(2002)[128]\end{array}$ & Phenylbutyrate & I & $\begin{array}{l}\text { i.v., } 375 \mathrm{mg} / \mathrm{kg} / \text { day } \\
7 / 14 \text { or } 21 / 28 \text { days } \\
\text { cont. infusion }\end{array}$ & 23 & $\begin{aligned} \text { MDS: } n & =9, \text { AML: } \\
n & =14\end{aligned}$ & $\begin{array}{c}2[9 \%] \\
2 \mathrm{HI}(21 / 28 \\
\text { schedule })\end{array}$ & $\begin{array}{l}\text { CNS toxicity, skin } \\
\text { reaction, } \\
\text { hypo-calcemia }\end{array}$ \\
\hline $\begin{array}{l}\text { Zhou et al. } \\
\text { (2002) [129] }\end{array}$ & $\begin{array}{c}\text { Phenylbutyrate + } \\
\text { ATRA }\end{array}$ & I & $\begin{array}{c}\text { i.v., } \\
200-400 \mathrm{mg} / \mathrm{kg} / \text { day } \\
25 \text { days }\end{array}$ & 5 & AML M3: $n=5$ & $\begin{array}{c}1[20 \%] \\
1 \text { RT-PCR neg. CR }\end{array}$ & $\begin{array}{l}\text { Transient CNS } \\
\text { depression }\end{array}$ \\
\hline $\begin{array}{l}\text { Odenike et al. } \\
(2006) \text { [130] }\end{array}$ & Depsipeptide & II & $\begin{array}{c}\text { i.v., } \\
18 \mathrm{mg} / \mathrm{m}^{2} / \text { dayday } 1, \\
8 \text { and } 15 \text { every } 28 \\
\text { days }\end{array}$ & 18 & AML: $n=18$ & $\begin{array}{c}2[11 \%] \\
2 \text { BM- blast } \\
\text { clearance }(\mathrm{t}(8 ; 21) \\
\text { and } \mathrm{t}(4 ; 21))\end{array}$ & $\begin{array}{l}\text { Nausea, vomiting, } \\
\text { fatigue }\end{array}$ \\
\hline $\begin{array}{l}\text { Byrd et al. } \\
(2005)[131]\end{array}$ & Depsipeptide & I & $\begin{array}{l}\text { i.v., } 13 \mathrm{mg} / \mathrm{m}^{2} \text { day } 1 \text {, } \\
8,15 \text { every } 28 \text { days }\end{array}$ & 10 & AML: $n=10$ & $\begin{array}{c}\text { Transient declines } \\
\text { in PB and BM } \\
\text { blasts }\end{array}$ & $\begin{array}{l}\text { Fatigue, vomiting, } \\
\text { nausea, tumor lysis } \\
\text { syndrome, } \\
\text { diarrhea }\end{array}$ \\
\hline $\begin{array}{l}\text { Giles et al. } \\
(2006) \text { [132] }\end{array}$ & LBH589 & I & $\begin{array}{c}\text { i.v., } 4.8-14 \mathrm{mg} / \mathrm{m}^{2} \text {, } \\
\text { days } 1-7 \text { every } 21 \\
\text { days }\end{array}$ & 14 & $\begin{array}{l}\text { AML: } n=13, \\
\text { MDS: } n=1\end{array}$ & $\begin{array}{l}\quad 8[57 \%] \\
8 \text { patients transient } \\
\text { decline in PB blasts }\end{array}$ & $\begin{array}{l}\text { QT-prolongation, } \\
\text { nausea, vomiting, } \\
\text { hypokalemia }\end{array}$ \\
\hline $\begin{array}{l}\text { Garcia-Manero } \\
\text { et al. (2005) } \\
{[133]}\end{array}$ & Vorinostat (SAHA) & I & $\begin{array}{c}\text { Oral, } 100-300 \mathrm{mg} \\
2-3 \times / \text { day, } 14 / 21 \\
\text { days }\end{array}$ & 35 & $\begin{aligned} \text { AML: } n=31, \\
\text { MDS: } n=3, \text { CML: } \\
n=1\end{aligned}$ & $\begin{array}{c}9[25 \%] \\
\begin{array}{c}\mathrm{CR}, 2 \mathrm{CRp}, 1 \mathrm{PR}, 5 \\
\text { complete marrow } \\
\text { responses }\end{array}\end{array}$ & $\begin{array}{l}\text { Nausea, vomiting, } \\
\text { diarrhea, } \\
\text { neutropenia, } \\
\text { typhlitis, fatigue }\end{array}$ \\
\hline $\begin{array}{l}\text { Gojo et al. } \\
(2007)[134]\end{array}$ & MS-275 & I & $\begin{array}{c}\text { Oral, } 4-10 \mathrm{mg} / \mathrm{m}^{2}, \\
1 \times \text { week for } 2 \text { or } 4 \\
\text { weeks }\end{array}$ & 38 & AML: $n=38$ & $\begin{array}{c}7[18 \%] \\
7 \mathrm{HI} \text {, transient } \\
\text { decline in PB and } \\
\text { BM blasts }\end{array}$ & $\begin{array}{l}\text { CNS toxicity, } \\
\text { infections, fatigue, } \\
\text { nausea, vomiting }\end{array}$ \\
\hline
\end{tabular}

Abbreviations. AML: acute myeloid leukaemia; ATRA: All-trans-Retinoic-Acid; BM: bone marrow CML: chronic myelogenous leukaemia; CNS: central nervous system; CR: complete remission; CRp: complete response with incomplete platelet recovery; HDACi: histone deacetylase inhibitors; HI: haematologic improvement; MDS: myelodysplastic syndrome; PB: peripheral blood; PR: partial response.

myeloid cells $[124,125]$ inducing the setup of different pilot studies of heterogeneous combination of these two drugs [17]. The response rate within these clinical trials reflects the morphological subtypes of MDS with overall response rates of $8 \%, 11 \%, 22 \%$, and $50 \%$ in the line with MDS subgroups ranging from IPSS low-risk, intermediate-I, intermediateII, to high-risk MDS, respectively. Interestingly, most of the responses were observed in the group with low-risk karyotypes [126].

In subsequent years, several clinical trials with other HDACi were started for therapy of MDS (as listed in Table 3). Most of these clinical trials with HDACi are in phase I indicating the preliminary experience with these drugs in MDS. Specific or pan-HDACi were phenylbutyrate (partially in combination all-trans retinoic acid), depsipeptide (romidepsin), LBH589 (panobinostat), SAHA (Vorinostat), and MS275/SDX275 (entinostat) in descending order according to the frequency of use. As these trials were conducted in a Phase I setting, the overall patient number is low and the primary endpoints were toxicity and safety; response rates, ranging from 9 to $57 \%$, were only secondary endpoints here.

An interesting aspect is the type of "biomarkers" which are used during these trials to describe the effects of HDACi on deacetylation $[15,17]$ : in the trials with valproic acid in combination with ATRA, the acetylation status of histone $\mathrm{H} 3$ and H4 in blood mononuclear cells as well as of the HDAC protein were determined. While missing other possibilities of sufficiently monitoring the bioactivity of HDACi, clinical effects such as transfusion requirements, white blood cell count, or percentage of immature cells (in the peripheral blood or bone marrow) were additionally used.

In summary, single agent clinical trials of HDACi have shown a good safety profile in patients with MDS, although the response rates observed so far are lower than for DNMT inhibitors, which is attributable to the predominant Phase I trial design conducted so far. 
4.2. Combination Therapy. Experimental data could demonstrate that DNA methylation interacts with histone deacetylase activity indicating the recursive complexity of epigenetics $[135,136]$. Therefore, it was expected that HDACi and DNMTi would show synergistic effects $[67,137]$. This synergistic effects could be explained by the known crosstalk between DNA methylation and histone modifications: (i) HDACs are activated by DNMT and by methylcytosinebinding proteins potentiating the gene silencing effect $[76,138]$, (ii) hypermethylated genes are resistant to reexpression by treatment with HDACis [139], and additionally (iii) DNMTi increases histone methylation and acetylation (such as H3K4) thus activating gene transcription [140]. Nevertheless, more detailed mechanisms of the synergistic effects of HDACi and DNMTi remain to be investigated. Our own experience with the DNMTi Zebularine and SAHA confirmed the synergy on apoptosis, proliferation inhibition, and differentiation in a pancreatic cancer model [141]. Therefore, analysis of sequential application of DNMTi and HDACi were performed in vitro and in vivo identifying that primary application of demethylating agent (low dose) following by an HDAC inhibitor show the best re-expression levels of hypermethylated genes [137, 142], which is in line with the concept of DNA methylation via the so-called de novo DNA methyltransferases during DNA replication [103].

Interestingly, combination therapy of MDS using DNMTi and HDACi is already ongoing (as listed in Table 4) using the combination of decitabine or azazytidine as DNMTi and VA (in one study in combination with ATRA) or phenylbutyrate as HDACi. The overall response rates are optimistic up to $54 \%$, whereas complete response was observed in up to $22 \%$. Nevertheless, the patient numbers of these clinical trials are small due to the Phase I/II setting and are therefore not powered for determining response rates. No unexpected toxicity profiles were seen. Specific details of these studies were in detail: the study of Gore et al. showed that reversed methylation during the first cycle of therapy correlates with therapy response. Interestingly, this was more often accompanied by induction of acetylation of histone $\mathrm{H} 3$ and $\mathrm{H} 4$ following administration of the DNMTi rather than of the HDACi [143]. Such convincing data could not be obtained using the HDAC inhibitor VA. In the study of Garcia-Manero et al., global methylation and p 15 promotor methylation did not differ between responders and nonresponders. Looking at HDACi effects, histone acetylation did not increase until application of highest dose level of VA, whereas the HDACi target $\mathrm{p} 21^{\mathrm{WAF} 1 / \mathrm{CIP} 1}$ increased during therapy [144]. Clinical benefit was observed in the trial of Blum et al. independently of whether with or without VA, confirming that this agent is not a potent HDACi [145]. Finally, the data of the study of Soriano et al. corroborated the findings of the other studies with VA that global mutation as well as induction of p21 and p14 mRNA did not correlate with therapy response [146].

In summary, the combination of HDACi with DNMTi as well as other combinations (including different cytotoxics, targeted therapies and radiation therapy as reviewed from Batty et al. [14]) still remains an interesting field for experimental investigations as well as for larger randomised trials based on available preclinical data in order to detect the best synergy of these agents.

\section{Conclusion and Outlook}

The heterogeneous nature of MDS demands differential therapy strategies, which reflects on the one hand prognostic subgroups, age, and performance status of the patients with MDS and on the other hand the associated pathogenesis pathways (see Figure 1 and Table 1). Until now, detailed insights into the pathogenesis of MDS have not been published. Yet, the factors driving progression as well their mechanism of interaction are still unclear. New insights came from the field of epigenetics, which admittedly leads to more complexity, too. First clinical trials give evidence that patients with MDS could benefit from epigenetic treatment with DNA methylation inhibitors and HDACi [14]. Nevertheless, many issues of HDACi remains completely unknown and pose clinical and translational challenges [74].

(i) As HDACi have been approved in the treatment of CTCL by the FDA, the mechanism of their selectivity is speculative postulating preferential induction of apoptosis in vitro [148], expression of HDAC2 in aggressive CTCL [149] as well as modulation of gene expression in vivo [150]. For that, further detailed molecular investigations of HDACi treated CTCL are urgently needed to better understand the molecular mechanisms of the reported excellent clinical results in CTCL and to confer these findings to other tumorous diseases like MDS.

(ii) As histone $\mathrm{H} 3$ and $\mathrm{H} 4$ acetylation are not correlated with clinical response $[110,111]$, surrogate markers have to be identified for therapy prognosis, controlling and terminating related to the patient and MDSrelated disease stage.

(iii) An additional task is to clarify specific pharmacological aspects of HDACi such as potency, isotype selectivity, application, and toxicity profile as well as mechanisms of resistance. These findings could support the decision on which HDACi are suitable for which MDS subgroups [151-154].

(iv) Finally, the sequential application strategy of HDACi with DNMTi or other cytotoxic drugs should be determined to optimize the additive or synergistic effects in the treatment of MDS [14].

For that, we are at the beginning of establishing a HDACinhibitor strategy in the complexity of therapeutic management of MDS.

\section{Conflict of Interests}

Matthias Ocker is a member of the scientific advisory board for panobinostat by Novartis Pharma GmbH. All other authors have no conflict of interest regarding this paper. 


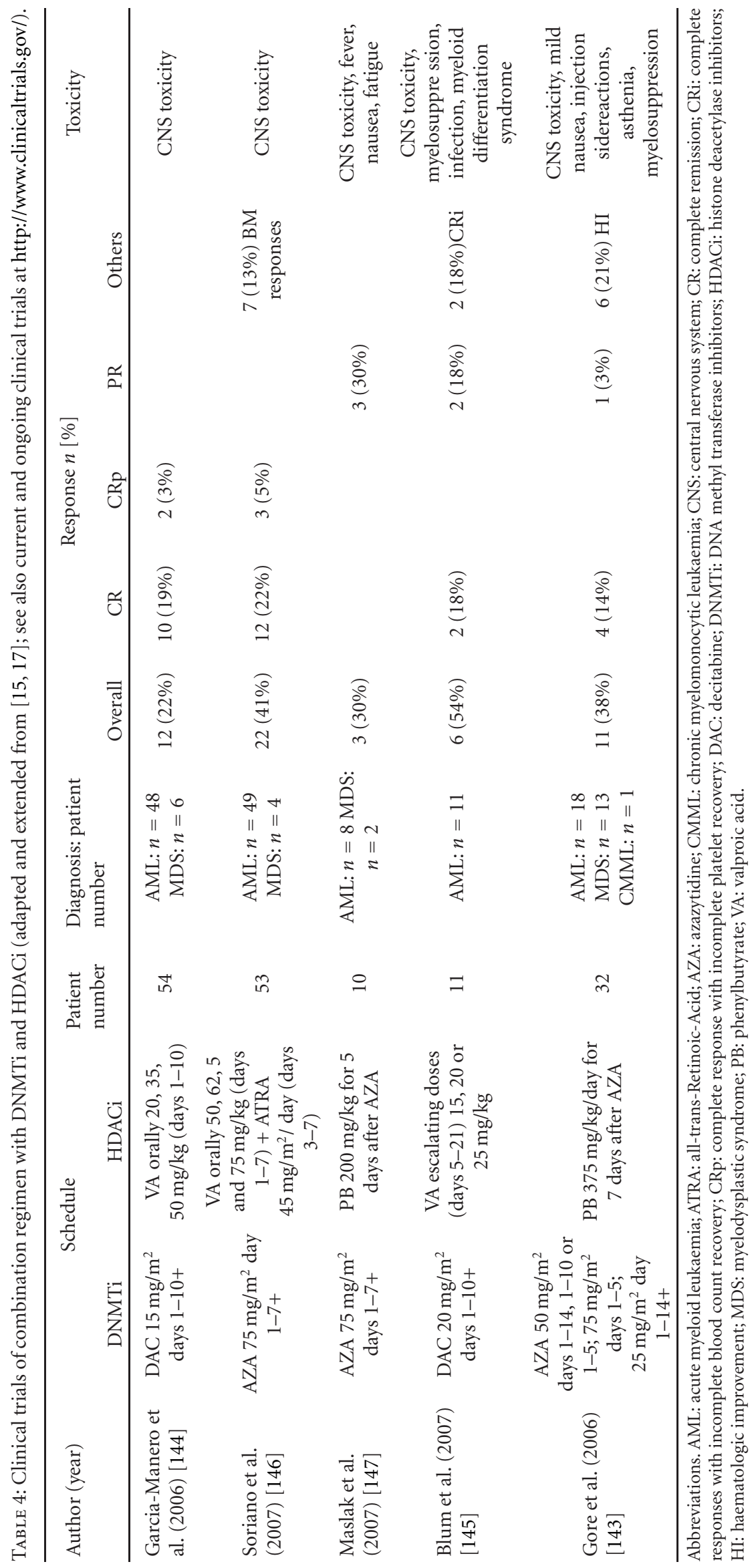




\section{Acknowledgments}

The authors would like to apologise to colleagues whose primary references could not be cited in this paper due to space limitations. B. Alinger and this study were supported by the research fund of the Paracelsus Medical University Salzburg (Grant no. 07/06/033). Additionally, T. Kiesslich was supported by the Jubiläumsfonds der Österreichischen Nationalbank (OeNB, Grant no. 12677) and the research fund of the Paracelsus Medical University Salzburg (Grant no. 08/07/037). This work is dedicated to the 60th birthday of Prof. Dr. O. Dietze (Director of the Institute of Pathology, Paracelsus Medical University/SALK, Salzburg, Austria).

\section{References}

[1] J. M. Bennett, D. Catovsky, M. T. Daniel et al., "Proposals for the classification of the myelodysplastic syndromes," British Journal of Haematology, vol. 51, no. 2, pp. 189-199, 1982.

[2] M. Cazzola and L. Malcovati, "Myelodysplastic syndromescoping with ineffective hematopoiesis," New England Journal of Medicine, vol. 352, no. 6, pp. 536-538, 2005.

[3] J. W. Vardiman, J. Thiele, D. A. Arber et al., "The 2008 revision of the World Health Organization (WHO) classification of myeloid neoplasms and acute leukemia: rationale and important changes," Blood, vol. 114, no. 5, pp. 937-951, 2009.

[4] S. S. Strom, V. Vélez-Bravo, and E. H. Estey, "Epidemiology of myelodysplastic syndromes," Seminars in Hematology, vol. 45 , no. 1, pp. 8-13, 2008.

[5] G. Leone, L. Mele, A. Pulsoni, F. Equitani, and L. Pagano, "The incidence of secondary leukemias," Haematologica, vol. 84, no. 10, pp. 937-945, 1999.

[6] S. J. Corey, M. D. Minden, D. L. Barber, H. Kantarjian, J. C. Y. Wang, and A. D. Schimmer, "Myelodysplastic syndromes: the complexity of stem-cell diseases," Nature Reviews Cancer, vol. 7, no. 2, pp. 118-129, 2007.

[7] P. Bernasconi, "Molecular pathways in myelodysplastic syndromes and acute myeloid leukemia: relationships and distinctions-a review," British Journal of Haematology, vol. 142, no. 5, pp. 695-708, 2008.

[8] W. H. Raskind, N. Tirumali, R. Jacobson et al., "Evidence for a multistep pathogenesis of a myelodysplastic syndrome," Blood, vol. 63, no. 6, pp. 1318-1323, 1984.

[9] C. Rosenfeld and A. List, "A hypothesis for the pathogenesis of myelodysplastic syndromes: implications for new therapies," Leukemia, vol. 14, no. 1, pp. 2-8, 2000.

[10] H. Hirai, "Molecular mechanisms of myelodysplastic syndrome," Japanese Journal of Clinical Oncology, vol. 33, no. 4, pp. 153-160, 2003.

[11] F. Nolte and W. K. Hofmann, "Myelodysplastic syndromes: molecular pathogenesis and genomic changes," Annals of Hematology, vol. 87, no. 10, pp. 777-795, 2008.

[12] P. Greenberg, C. Cox, M. M. LeBeau et al., "International scoring system for evaluating prognosis in myelodysplastic syndromes," Blood, vol. 89, no. 6, pp. 2079-2088, 1997.

[13] P. L. Greenberg, "Current therapeutic approaches for patients with myelodysplastic syndromes," British Journal of Haematology, vol. 150, no. 2, pp. 131-143, 2010.

[14] N. Batty, G. G. Malouf, and J. P. J. Issa, "Histone deacetylase inhibitors as anti-neoplastic agents," Cancer Letters, vol. 280, no. 2, pp. 192-200, 2009.
[15] E. A. Griffiths and S. D. Gore, "DNA methyltransferase and histone deacetylase inhibitors in the treatment of myelodysplastic syndromes," Seminars in Hematology, vol. 45, no. 1, pp. 23-30, 2008.

[16] J. P. Issa, "Epigenetic changes in the myelodysplastic syndrome," Hematology/Oncology Clinics of North America, vol. 24, no. 2, pp. 317-330, 2010.

[17] A. Kuendgen and M. Lübbert, "Current status of epigenetic treatment in myelodysplastic syndromes," Annals of Hematology, vol. 87, no. 8, pp. 601-611, 2008.

[18] S. D. Nimer, "Myelodysplastic syndromes," Blood, vol. 111, no. 10, pp. 4841-4851, 2008.

[19] T. Vallespí, M. Imbert, C. Mecucci, C. Preudhomme, and P. Fenaux, "Diagnosis, classification, and cytogenetics of myelodysplastic syndromes," Haematologica, vol. 83, no. 3, pp. 258-275, 1998.

[20] M. L. Heaney and D. W. Golde, "Myelodysplasia," New England Journal of Medicine, vol. 340, no. 21, pp. 1649-1660, 1999.

[21] A. Schmitt-Graeff, D. Mattern, H. Köhler, J. Hezel, and M. Lübbert, "Myelodysplastic syndromes: aspects of hematopathologic diagnosis," Pathologe, vol. 21, no. 1, pp. 1-15, 2000 .

[22] D. P. Steensma, "The changing classification of myelodysplastic syndromes: what's in a name?" Hematology-American Society of Hematology. Education Program, pp. 645-655, 2009.

[23] L. Malcovati, U. Germing, A. Kuendgen et al., "Timedependent prognostic scoring system for predicting survival and leukemic evolution in myelodysplastic syndromes," Journal of Clinical Oncology, vol. 25, no. 23, pp. 3503-3510, 2007.

[24] G. J. Mufti, "Pathobiology, classification, and diagnosis of myelodysplastic syndrome," Best Practice and Research: Clinical Haematology, vol. 17, no. 4, pp. 543-557, 2004.

[25] J. Pedersen-Bjergaard, M. K. Andersen, and D. H. Christiansen, "Therapy-related acute myeloid leukemia and myelodysplasia after high-dose chemotherapy and autologous stem cell transplantation," Blood, vol. 95, no. 11, pp. 3273-3279, 2000.

[26] F. J. Giles and H. P. Koeffler, "Secondary myelodysplastic syndromes and leukemias," Current Opinion in Hematology, vol. 1, no. 4, pp. 256-260, 1994.

[27] J. Pedersen-Bjergaard, M. K. Andersen, D. H. Christiansen, and C. Nerlov, "Genetic pathways in therapy-related myelodysplasia and acute myeloid leukemia," Blood, vol. 99, no. 6, pp. 1909-1912, 2002.

[28] C. Aul, U. Germing, N. Gattermann, and H. Minning, "Increasing incidence of myelodysplastic syndromes: real or fictitious?” Leukemia Research, vol. 22, no. 1, pp. 93-100, 1998.

[29] C. Aul, N. Gattermann, and W. Schneider, "Age-related incidence and other epidemiological aspects of myelodysplastic syndromes," British Journal of Haematology, vol. 82, no. 2, pp. 358-367, 1992.

[30] A. Radlund, T. Thiede, S. Hansen, M. Carlsson, and L. Engquist, "Incidence of myelodysplastic syndromes in a Swedish population," European Journal of Haematology, vol. 54, no. 3, pp. 153-156, 1995.

[31] P. J. Williamson, A. R. Kruger, P. I. Reynolds, T. J. Hamblin, and D. G. Oscier, "Establishing the incidence of myelodysplastic syndrome," British Journal of Haematology, vol. 87, no. 4, pp. 743-745, 1994.

[32] N. Casadevall, P. Durieux, S. Dubois et al., "Health, economic, and quality-of-life effects of erythropoietin and 
granulocyte colony-stimulating factor for the treatment of myelodysplastic syndromes: a randomized, controlled trial," Blood, vol. 104, no. 2, pp. 321-327, 2004.

[33] T. F. Goss, A. Szende, C. Schaefer et al., "Cost effectiveness of lenalidomide in the treatment of transfusion-dependent myelodysplastic syndromes in the United States," Cancer Control, vol. 13, supplement, pp. 17-25, 2006.

[34] P. L. Greenberg, L. E. Cosler, S. A. Ferro, and G. H. Lyman, "The costs of drugs used to treat myelodysplastic syndromes following national comprehensive cancer network guidelines," Journal of the National Comprehensive Cancer Network, vol. 6, no. 9, pp. 942-953, 2008.

[35] R. Kemmerling, D. Neureiter, V. Faber et al., "Incidence and other aspects of myelodysplastic syndrome in the Austrian federal state Salzburg," Pathology Research and Practice, vol. 203, no. 5, pp. 392-392, 2007.

[36] C. Aul, D. T. Bowen, and Y. Yoshida, "Pathogenesis, etiology and epidemiology of myelodysplastic syndromes," Haematologica, vol. 83, no. 1, pp. 71-86, 1998.

[37] A. Raza, "Hypothesis: myelodysplastic syndromes may have a viral etiology," International Journal of Hematology, vol. 68, no. 3, pp. 245-256, 1998.

[38] P. Mhawech and A. Saleem, "Myelodysplastic syndrome: review of the cytogenetic and molecular data," Critical Reviews in Oncology/Hematology, vol. 40, no. 3, pp. 229-238, 2001.

[39] H. J. Olney and M. M. Le Beau, "The cytogenetics of myelodysplastic syndromes," Best Practice and Research: Clinical Haematology, vol. 14, no. 3, pp. 479-495, 2001.

[40] A. List, S. Kurtin, D. J. Roe et al., "Efficacy of lenalidomide in myelodysplastic syndromes," New England Journal of Medicine, vol. 352, no. 6, pp. 549-557, 2005.

[41] A. List, G. Dewald, J. Bennett et al., "Lenalidomide in the myelodysplastic syndrome with chromosome 5q deletion," New England Journal of Medicine, vol. 355, no. 14, pp. 1456$1465,2006$.

[42] C. L. O’Keefe, R. Tiu, L. P. Gondek et al., "High-resolution genomic arrays facilitate detection of novel cryptic chromosomal lesions in myelodysplastic syndromes," Experimental Hematology, vol. 35, no. 2, pp. 240-251, 2007.

[43] A. G. Knudson, "Hereditary cancer: two hits revisited," Journal of Cancer Research and Clinical Oncology, vol. 122, no. 3, pp. 135-140, 1996.

[44] H. Harada, Y. Harada, H. Tanaka, A. Kimura, and T. Inaba, "Implications of somatic mutations in the AML1 gene in radiation-associated and therapy-related myelodysplastic syndrome/acute myeloid leukemia," Blood, vol. 101, no. 2, pp. 673-680, 2003.

[45] P. Ganly, L. C. Walker, and C. M. Morris, "Familial mutations of the transcription factor RUNX1 (AML1, CBFA2) predispose to acute myeloid leukemia," Leukemia and Lymphoma, vol. 45, no. 1, pp. 1-10, 2004.

[46] W. J. Song, M. G. Sullivan, R. D. Legare et al., "Haploinsufficiency of CBFA2 causes familial thrombocytopenia with propensity to develop acute myelogenous leukaemia," Nature Genetics, vol. 23, no. 2, pp. 166-175, 1999.

[47] J. Pedersen-Bjergaard, D. H. Christiansen, F. Desta, and M. K. Andersen, "Alternative genetic pathways and cooperating genetic abnormalities in the pathogenesis of therapy-related myelodysplasia and acute myeloid leukemia," Leukemia, vol. 20, no. 11, pp. 1943-1949, 2006.

[48] G. B. Tennant, V. Walsh, L. N. Truran, P. Edwards, K. I. Mills, and A. K. Burnett, "Abnormalities of adherent layers grown from bone marrow of patients with myelodysplasia,"
British Journal of Haematology, vol. 111, no. 3, pp. 853-862, 2000.

[49] E. Flores-Figueroa, G. Gutiérrez-Espíndola, J. J. Montesinos, R. M. Arana-Trejo, and H. Mayani, "In vitro characterization of hematopoietic microenvironment cells from patients with myelodysplastic syndrome," Leukemia Research, vol. 26, no. 7, pp. 677-686, 2002.

[50] D. L. Stirewalt, A. J. Mhyre, M. Marcondes et al., “Tumour necrosis factor-induced gene expression in human marrow stroma: clues to the pathophysiology of MDS?" British Journal of Haematology, vol. 140, no. 4, pp. 444-453, 2008.

[51] W. T. Bellamy, L. Richter, D. Sirjani et al., "Vascular endothelial cell growth factor is an autocrine promoter of abnormal localized immature myeloid precursors and leukemia progenitor formation in myelodysplastic syndromes," Blood, vol. 97, no. 5, pp. 1427-1434, 2001.

[52] E. Travaglino, C. Benatti, L. Malcovati et al., "Biological and clinical relevance of matrix metalloproteinases 2 and 9 in acute myeloid leukaemias and myelodysplastic syndromes," European Journal of Haematology, vol. 80, no. 3, pp. 216-226, 2008.

[53] D. Campioni, P. Secchiero, F. Corallini et al., "Evidence for a role of TNF-related apoptosis-inducing ligand (TRAIL) in the anemia of myelodysplastic syndromes," American Journal of Pathology, vol. 166, no. 2, pp. 557-563, 2005.

[54] T. Braun, G. Carvalho, A. Coquelle et al., "NF- $\kappa$ B constitutes a potential therapeutic target in high-risk myelodysplastic syndrome," Blood, vol. 107, no. 3, pp. 1156-1165, 2006.

[55] D. M. B. Kerbauy, V. Lesnikov, N. Abbasi, S. Seal, B. Scott, and H. Joachim Deeg, "NF- $\kappa$ B and FLIP in arsenic trioxide (ATO)-induced apoptosis in myelodysplastic syndromes (MDSs)," Blood, vol. 106, no. 12, pp. 3917-3925, 2005.

[56] S. Buonamici, D. Li, Y. Chi et al., "EVI1 induces myelodysplastic syndrome in mice," Journal of Clinical Investigation, vol. 114, no. 5, pp. 713-719, 2004.

[57] Y. W. Lin, C. Slape, Z. Zhang, and P. D. Aplan, "NUP98HOXD13 transgenic mice develop a highly penetrant, severe myelodysplastic syndrome that progresses to acute leukemia," Blood, vol. 106, no. 1, pp. 287-295, 2005.

[58] S. Grisendi, R. Bernardi, M. Rossi et al., "Role of nucleophosmin in embryonic development and tumorigenesis," Nature, vol. 437, no. 7055, pp. 147-153, 2005.

[59] M. A. Sekeres, "Treatment of MDS: something old, something new, something borrowed," Hematology-American Society of Hematology. Education Program, pp. 656-663, 2009.

[60] H. Kantarjian, S. O’Brien, J. Cortes et al., “Therapeutic advances in leukemia and myelodysplastic syndrome over the past 40 years," Cancer, vol. 113, no. 7, pp. 1933-1952, 2008.

[61] E. Hellström-Lindberg and L. Malcovati, "Supportive care and use of hematopoietic growth factors in myelodysplastic syndromes," Seminars in Hematology, vol. 45, no. 1, pp. 1422, 2008.

[62] R. Tehranchi, B. Fadeel, A. M. Forsblom et al., "Granulocyte colony-stimulating factor inhibits spontaneous cytochrome $\mathrm{C}$ release and mitochondria-dependent apoptosis of myelodysplastic syndrome hematopoietic progenitors," Blood, vol. 101, no. 3, pp. 1080-1086, 2003.

[63] M. Takatoku, T. Uchiyama, S. Okamoto et al., "Retrospective nationwide survey of Japanese patients with transfusiondependent MDS and aplastic anemia highlights the negative impact of iron overload on morbidity/mortality," European Journal of Haematology, vol. 78, no. 6, pp. 487-494, 2007.

[64] G. Metzgeroth, D. Dinter, B. Schultheis et al., "Deferasirox in MDS patients with transfusion-caused iron overload- 
a phase-II study," Annals of Hematology, vol. 88, no. 4, pp. 301-310, 2009.

[65] E. M. Sloand, L. Mainwaring, M. Fuhrer et al., "Preferential suppression of trisomy 8 compared with normal hematopoietic cell growth by autologous lymphocytes in patients with trisomy 8 myelodysplastic syndrome," Blood, vol. 106, no. 3, pp. 841-851, 2005.

[66] C. Selleri, J. P. Maciejewski, L. Catalano et al., "Effects of cyclosporine on hematopoietic and immune functions in patients with hypoplastic myelodysplasia: in vitro and in vivo studies," Cancer, vol. 95, no. 9, pp. 1911-1922, 2002.

[67] O. Galm, J. G. Herman, and S. B. Baylin, "The fundamental role of epigenetics in hematopoietic malignancies," Blood Reviews, vol. 20, no. 1, pp. 1-13, 2006.

[68] K. Anargyrou, T. P. Vassilakopoulos, M. K. Angelopoulou, and E. Terpos, "Incorporating novel agents in the treatment of myelodysplastic syndromes," Leukemia Research, vol. 34, no. 1, pp. 6-17, 2010.

[69] E. Estey, "Acute myeloid leukemia and myelodysplastic syndromes in older patients," Journal of Clinical Oncology, vol. 25, no. 14, pp. 1908-1915, 2007.

[70] E. H. Estey, P. F. Thall, J. E. Cortes et al., "Comparison of idarubicin + ara-C-, fludarabine + ara-C-, and topotecan + ara-C-based regimens in treatment of newly diagnosed acute myeloid leukemia, refractory anemia with excess blasts in transformation, or refractory anemia with excess blasts," Blood, vol. 98, no. 13, pp. 3575-3583, 2001.

[71] G. Mufti, A. F. List, S. D. Gore, and A. Y. Ho, "Myelodysplastic syndrome," Hematology —American Society of Hematology. Education Program, pp. 176-199, 2003.

[72] S. Faderl and H. M. Kantarjian, "Novel therapies for myelodysplastic syndromes," Cancer, vol. 101, no. 2, pp. 226241, 2004.

[73] A. J. M. De Ruijter, A. H. Van Gennip, H. N. Caron, S. Kemp, and A. B. P. Van Kuilenburg, "Histone deacetylases (HDACs): characterization of the classical HDAC family," Biochemical Journal, vol. 370, no. 3, pp. 737-749, 2003.

[74] W. S. Xu, R. B. Parmigiani, and P. A. Marks, "Histone deacetylase inhibitors: molecular mechanisms of action," Oncogene, vol. 26, no. 37, pp. 5541-5552, 2007.

[75] D. Hanahan and R. A. Weinberg, "The hallmarks of cancer," Cell, vol. 100, no. 1, pp. 57-70, 2000.

[76] J. G. Herman and S. B. Baylin, "Gene silencing in cancer in association with promoter hypermethylation," New England Journal of Medicine, vol. 349, no. 21, pp. 2042-2054, 2003.

[77] M. Esteller, "Molecular origins of cancer: epigenetics in cancer," New England Journal of Medicine, vol. 358, no. 11, pp. 1148-1159, 2008.

[78] P. A. Jones and S. B. Baylin, "The fundamental role of epigenetic events in cancer," Nature Reviews Genetics, vol. 3, no. 6, pp. 415-428, 2002.

[79] H. Santos-Rosa and C. Caldas, "Chromatin modifier enzymes, the histone code and cancer," European Journal of Cancer, vol. 41, no. 16, pp. 2381-2402, 2005.

[80] X. De La Cruz, S. Lois, S. Sánchez-Molina, and M. A. Martínez-Balbás, "Do protein motifs read the histone code?" BioEssays, vol. 27, no. 2, pp. 164-175, 2005.

[81] R. Schneider-Stock and M. Ocker, "Epigenetic therapy in cancer: molecular background and clinical development of histone deacetylase and DNA methyltransferase inhibitors," The Investigational Drugs Journal, vol. 10, no. 8, pp. 557-561, 2007.
[82] K. Daly and S. P. Shirazi-Beechey, "Microarray analysis of butyrate regulated genes in colonic epithelial cells," DNA and Cell Biology, vol. 25, no. 1, pp. 49-62, 2006.

[83] S. G. Gray, C. N. Qian, K. Furge, X. Guo, and B. T. Teh, "Microarray profiling of the effects of histone deacetylase inhibitors on gene expression in cancer cell lines," International Journal of Oncology, vol. 24, no. 4, pp. 773-795, 2004.

[84] S. Y. Roth, J. M. Denu, and C. D. Allis, "Histone acetyltransferases," Annual Review of Biochemistry, vol. 70, pp. 81-120, 2001.

[85] R. Marmorstein and S. Y. Roth, "Histone acetyltransferases: function, structure, and catalysis," Current Opinion in Genetics and Development, vol. 11, no. 2, pp. 155-161, 2001.

[86] O. Witt, H. E. Deubzer, T. Milde, and I. Oehme, "HDAC family: what are the cancer relevant targets?" Cancer Letters, vol. 277, no. 1, pp. 8-21, 2009.

[87] M. Ocker, "Deacetylase inhibitors-focus on non-histone targets and effects," World Journal of Biological Chemistry, vol. 1, no. 5, pp. 55-61, 2010.

[88] L. Gao, M. A. Cueto, F. Asselbergs, and P. Atadja, "Cloning and functional characterization of HDAC11, a novel member of the human histone deacetylase family," Journal of Biological Chemistry, vol. 277, no. 28, pp. 25748-25755, 2002.

[89] G. P. Delcuve, M. Rastegar, and J. R. Davie, "Epigenetic control," Journal of Cellular Physiology, vol. 219, no. 2, pp. 243-250, 2009.

[90] M. Spivakov and A. G. Fisher, "Epigenetic signatures of stemcell identity," Nature Reviews Genetics, vol. 8, no. 4, pp. 263271, 2007.

[91] J. H. Choi, H. J. Kwon, B. I. Yoon et al., "Expression profile of histone deacetylase 1 in gastric cancer tissues," Japanese Journal of Cancer Research, vol. 92, no. 12, pp. 1300-1304, 2001.

[92] Z. Zhang, H. Yamashita, T. Toyama et al., "Quantitation of HDAC1 mRNA expression in invasive carcinoma of the breast," Breast Cancer Research and Treatment, vol. 94, no. 1, pp. 11-16, 2005.

[93] A. J. Wilson, D. S. Byun, N. Popova et al., "Histone deacetylase 3 (HDAC3) and other class I HDACs regulate colon cell maturation and p21 expression and are deregulated in human colon cancer," Journal of Biological Chemistry, vol. 281, no. 19, pp. 13548-13558, 2006.

[94] Z. Zhang, H. Yamashita, T. Toyama et al., "HDAC6 expression is correlated with better survival in breast cancer," Clinical Cancer Research, vol. 10, no. 20, pp. 6962-6968, 2004.

[95] P. A. Marks and W. S. Xu, "Histone deacetylase inhibitors: potential in cancer therapy," Journal of Cellular Biochemistry, vol. 107, no. 4, pp. 600-608, 2009.

[96] P. A. Marks and R. Breslow, "Dimethyl sulfoxide to vorinostat: development of this histone deacetylase inhibitor as an anticancer drug," Nature Biotechnology, vol. 25, no. 1, pp. 8490, 2007.

[97] P. A. Marks, R. A. Rifkind, V. M. Richon, R. Breslow, T. Miller, and W. K. Kelly, "Histone deacetylases and cancer: causes and therapies," Nature Reviews Cancer, vol. 1, no. 3, pp. 194-202, 2001.

[98] S. Minucci and P. G. Pelicci, "Histone deacetylase inhibitors and the promise of epigenetic (and more) treatments for cancer," Nature Reviews Cancer, vol. 6, no. 1, pp. 38-51, 2006.

[99] M. Ocker and R. Schneider-Stock, "Histone deacetylase inhibitors: signalling towards p21," International Journal of Biochemistry and Cell Biology, vol. 39, no. 7-8, pp. 1367-1374, 2007. 
[100] V. M. Richon, T. W. Sandhoff, R. A. Rifkind, and P. A. Marks, "Histone deacetylase inhibitor selectively induces p21WAF1 expressjon and gene-associated histone acetylation," Proceedings of the National Academy of Sciences of the United States of America, vol. 97, no. 18, pp. 10014-10019, 2000.

[101] C. Y. Gui, L. Ngo, W. S. Xu, V. M. Richon, and P. A. Marks, "Histone deacetylase (HDAC) inhibitor activation of p21 involves changes in promoter-associated proteins, including HDAC1," Proceedings of the National Academy of Sciences of the United States of America, vol. 101, no. 5, pp. 1241-1246, 2004.

[102] P. Di Fazio, R. Schneider-Stock, D. Neureiter et al., "The pan-deacetylase inhibitor panobinostat inhibits growth of hepatocellular carcinoma models by alternative pathways of apoptosis," Cellular Oncology, vol. 32, no. 4, pp. 285-300, 2010.

[103] S. Zopf, D. Neureiter, S. Bouralexis et al., "Differential response of p53 and p21 on HDAC inhibitor-mediated apoptosis in HCT116 colon cancer cells in vitro and in vivo," International Journal of Oncology, vol. 31, no. 6, pp. 13911402, 2007.

[104] R. W. Johnstone and J. D. Licht, "Histone deacetylase inhibitors in cancer therapy: is transcription the primary target?” Cancer Cell, vol. 4, no. 1, pp. 13-18, 2003.

[105] K. L. Norris, J. Y. Lee, and T. P. Yao, "Acetylation goes global: the emergence of acetylation biology," Science Signaling, vol. 2, no. 97, p. e76, 2009.

[106] K. T. Smith and J. L. Workman, "Introducing the acetylome," Nature Biotechnology, vol. 27, no. 10, pp. 917-919, 2009.

[107] C. Choudhary, C. Kumar, F. Gnad et al., "Lysine acetylation targets protein complexes and co-regulates major cellular functions," Science, vol. 325, no. 5942, pp. 834-840, 2009.

[108] S. C. Kim, R. Sprung, Y. Chen et al., "Substrate and functional diversity of lysine acetylation revealed by a proteomics survey," Molecular Cell, vol. 23, no. 4, pp. 607-618, 2006.

[109] K. Sadoul, C. Boyault, M. Pabion, and S. Khochbin, "Regulation of protein turnover by acetyltransferases and deacetylases," Biochimie, vol. 90, no. 2, pp. 306-312, 2008.

[110] H. M. Prince, M. J. Bishton, and S. J. Harrison, "Clinical studies of histone deacetylase inhibitors," Clinical Cancer Research, vol. 15, no. 12, pp. 3958-3969, 2009.

[111] A. A. Lane and B. A. Chabner, "Histone deacetylase inhibitors in cancer therapy," Journal of Clinical Oncology, vol. 27, no. 32, pp. 5459-5468, 2009.

[112] Q. C. Ryan, D. Headlee, M. Acharya et al., "Phase I and pharmacokinetic study of MS-275, a histone deacetylase inhibitor, in patients with advanced and refractory solid tumors or lymphoma," Journal of Clinical Oncology, vol. 23, no. 17, pp. 3912-3922, 2005.

[113] W. K. Kelly, O. A. O’Connor, L. M. Krug et al., "Phase I study of an oral histone deacetylase inhibitor, suberoylanilide hydroxamic acid, in patients with advanced cancer," Journal of Clinical Oncology, vol. 23, no. 17, pp. 3923-3931, 2005.

[114] E. H. Rubin, N. G. B. Agrawal, E. J. Friedman et al., "A study to determine the effects of food and multiple dosing on the pharmacokinetics of vorinostat given orally to patients with advanced cancer," Clinical Cancer Research, vol. 12, no. 23, pp. 7039-7045, 2006.

[115] V. Sandor, S. Bakke, R. W. Robey et al., "Phase I trial of the histone deacetylase inhibitor, depsipeptide (FR901228, NSC 630176), in patients with refractory neoplasms," Clinical Cancer Research, vol. 8, no. 3, pp. 718-728, 2002.

[116] G. Garcia-Manero, S. Assouline, J. Cortes et al., "Phase 1 study of the oral isotype specific histone deacetylase inhibitor
MGCD0103 in leukemia," Blood, vol. 112, no. 4, pp. 981-989, 2008.

[117] G. Garcia-Manero, H. Yang, C. Bueso-Ramos et al., "Phase 1 study of the histone deacetylase inhibitor vorinostat (suberoylanilide hydroxamic acid [SAHA]) in patients with advanced leukemias and myelodysplastic syndromes," Blood, vol. 111, no. 3, pp. 1060-1066, 2008.

[118] E. Lech-Maranda, E. Robak, A. Korycka, and T. Robak, "Depsipeptide (FK228) as a novel histone deacetylase inhibitor: mechanism of action and anticancer activity," Mini-Reviews in Medicinal Chemistry, vol. 7, no. 10, pp. 1062-1069, 2007.

[119] T. Jenuwein and C. D. Allis, "Translating the histone code," Science, vol. 293, no. 5532, pp. 1074-1080, 2001.

[120] T. E. Fandy, J. G. Herman, P. Kerns et al., "Early epigenetic changes and DNA damage do not predict clinical response in an overlapping schedule of 5-azacytidine and entinostat in patients with myeloid malignancies," Blood, vol. 114, no. 13, pp. 2764-2773, 2009.

[121] M. E. Figueroa, L. Skrabanek, Y. Li et al., "MDS and secondary AML display unique patterns and abundance of aberrant DNA methylation," Blood, vol. 114, no. 16, pp. 3448-3458, 2009.

[122] M. E. Figueroa, A. Melnick, and J. M. Greally, "Genome-wide determination of DNA methylation by Hpa II tiny fragment enrichment by ligation-mediated PCR (HELP) for the study of acute leukemias," Methods in Molecular Biology, vol. 538, pp. 395-407, 2009.

[123] V. Gelsi-Boyer, V. Trouplin, J. Adélaïde et al., "Mutations of polycomb-associated gene ASXL1 in myelodysplastic syndromes and chronic myelomonocytic leukaemia," British Journal of Haematology, vol. 145, no. 6, pp. 788-800, 2009.

[124] M. Göttlicher, S. Minucci, P. Zhu et al., "Valproic acid defines a novel class of HDAC inhibitors inducing differentiation of transformed cells," EMBO Journal, vol. 20, no. 24, pp. 69696978, 2002.

[125] C. J. Phiel, F. Zhang, E. Y. Huang, M. G. Guenther, M. A. Lazar, and P. S. Klein, "Histone deacetylase is a direct target of valproic acid, a potent anticonvulsant, mood stabilizer, and teratogen," Journal of Biological Chemistry, vol. 276, no. 39, pp. 36734-36741, 2001.

[126] A. Kuendgen, C. Strupp, M. Aivado et al., "Treatment of myelodysplastic syndromes with valproic acid alone or in combination with all-trans retinoic acid," Blood, vol. 104, no. 5, pp. 1266-1269, 2004.

[127] S. D. Gore, L. J. Weng, S. Zhai et al., "Impact of the putative differentiating agent sodium phenylbutyrate on myelodysplastic syndromes and acute myeloid leukemia," Clinical Cancer Research, vol. 7, no. 8, pp. 2330-2339, 2001.

[128] S. D. Gore, L. J. Weng, W. D. Figg et al., "Impact of prolonged infusions of the putative differentiating agent sodium phenylbutyrate on myelodysplastic syndromes and acute myeloid leukemia," Clinical Cancer Research, vol. 8, no. 4, pp. 963-970, 2002.

[129] D.-C. Zhou, S. H. Kim, W. Ding, C. Schultz, R. P. Warrell Jr., and R. E. Gallagher, "Frequent mutations in the ligandbinding domain of PML-RAR $\alpha$ after multiple relapses of acute promyelocytic leukemia: analysis for functional relationship to response to all-trans retinoic acid and histone deacetylase inhibitors in vitro and in vivo," Blood, vol. 99, no. 4, pp. 1356-1363, 2002.

[130] O. M. Odenike, S. Alkan, D. Sher et al., "The histone deacetylase inhibitor (HDI) depsipeptide has differential activity in core binding factor AML," Blood, vol. 108, no. 11, p. 553A, 2006. 
[131] J. C. Byrd, G. Marcucci, M. R. Parthun et al., "A phase 1 and pharmacodynamic study of depsipeptide (FK228) in chronic lymphocytic leukemia and acute myeloid leukemia," Blood, vol. 105, no. 3, pp. 959-967, 2005.

[132] F. Giles, T. Fischer, J. Cortes et al., "A phase I study of intravenous LBH589, a novel cinnamic hydroxamic acid analogue histone deacetylase inhibitor, in patients with refractory hematologic malignancies," Clinical Cancer Research, vol. 12, no. 15 , pp. 4628-4635, 2006.

[133] G. Garcia-Manero, H. Yang, B. Sanchez-Gonzalez et al., "Final results of a phase I study of the histone deacetylase inhibitor vorinostat (suberoyanilide hydroxamic acid, SAHA), in patients with leukemia and myelodysplastic syndrome," Blood, vol. 106, no. 11, p. 785A, 2005.

[134] I. Gojo, A. Jiemjit, J. B. Trepel et al., "Phase 1 and pharmacologic study of MS-275, a histone deacetylase inhibitor, in adults with refractory and relapsed acute leukemias," Blood, vol. 109, no. 7, pp. 2781-2790, 2007.

[135] F. Fuks, W. A. Burgers, A. Brehm, L. Hughes-Davies, and T. Kouzarides, "DNA methyltransferase Dnmtl associates with histone deacetylase activity," Nature Genetics, vol. 24, no. 1, pp. 88-91, 2000.

[136] M. R. Rountree, K. E. Bachman, and S. B. Baylin, "DNMT1 binds HDAC2 and a new co-repressor, DMAP1, to form a complex at replication foci," Nature Genetics, vol. 25, no. 3, pp. 269-277, 2000.

[137] E. E. Cameron, K. E. Bachman, S. Myöhänen, J. G. Herman, and S. B. Baylin, "Synergy of demethylation and histone deacetylase inhibition in the re-expression of genes silenced in cancer," Nature Genetics, vol. 21, no. 1, pp. 103-107, 1999.

[138] L. K. Jones and V. Saha, "Chromatin modification, leukaemia and implications for therapy," British Journal of Haematology, vol. 118, no. 3, pp. 714-727, 2002.

[139] J. A. Fahrner, S. Eguchi, J. G. Herman, and S. B. Baylin, "Dependence of histone modifications and gene expression on DNA hypermethylation in cancer," Cancer Research, vol. 62, no. 24, pp. 7213-7218, 2002.

[140] C. T. Nguyen, D. J. Weisenberger, M. Velicescu et al., "Histone $\mathrm{H} 3$-lysine 9 methylation is associated with aberrant gene silencing in cancer cells and is rapidly reversed by 5 -aza- $2^{\prime}-$ deoxycytidine," Cancer Research, vol. 62, no. 22, pp. 64566461, 2002.

[141] D. Neureiter, S. Zopf, T. Leu et al., "Apoptosis, proliferation and differentiation patterns are influenced by Zebularine and SAHA in pancreatic cancer models," Scandinavian Journal of Gastroenterology, vol. 42, no. 1, pp. 103-116, 2007.

[142] H. Suzuki, E. Gabrielson, W. Chen et al., "A genomic screen for genes upregulated by demethylation and histone deacetylase inhibition in human colorectal cancer," Nature Genetics, vol. 31, no. 2, pp. 141-149, 2002.

[143] S. D. Gore, S. Baylin, E. Sugar et al., "Combined DNA methyltransferase and histone deacetylase inhibition in the treatment of myeloid neoplasms," Cancer Research, vol. 66, no. 12, pp. 6361-6369, 2006.

[144] G. Garcia-Manero, H. M. Kantarjian, B. Sanchez-Gonzalez et al., "Phase $1 / 2$ study of the combination of 5 -aza-2'deoxycytidine with valproic acid in patients with leukemia," Blood, vol. 108, no. 10, pp. 3271-3279, 2006.

[145] W. Blum, R. B. Klisovic, B. Hackanson et al., "Phase I study of decitabine alone or in combination with valproic acid in acute myeloid leukemia," Journal of Clinical Oncology, vol. 25, no. 25, pp. 3884-3891, 2007.

[146] A. O. Soriano, H. Yang, S. Faderl et al., "Safety and clinical activity of the combination of 5-azacytidine, valproic acid, and all-trans retinoic acid in acute myeloid leukemia and myelodysplastic syndrome," Blood, vol. 110, no. 7, pp. 23022308, 2007.

[147] P. Maslak, S. Chanel, L. H. Camacho et al., "Pilot study of combination transcriptional modulation therapy with sodium phenylbutyrate and 5-azacytidine in patients with acute myeloid leukemia or myelodysplastic syndrome," Leukemia, vol. 20, no. 2, pp. 212-217, 2006.

[148] C. Zhang, V. Richon, X. Ni, R. Talpur, and M. Duvic, "Selective induction of apoptosis by histone deacetylase inhibitor SAHA in cutaneous T-cell lymphoma cells: relevance to mechanism of therapeutic action," Journal of Investigative Dermatology, vol. 125, no. 5, pp. 1045-1052, 2005.

[149] L. Marquard, L. M. Gjerdrum, I. J. Christensen, P. B. Jensen, M. Sehested, and E. Ralfkiaer, "Prognostic significance of the therapeutic targets histone deacetylase 1, 2, 6 and acetylated histone H4 in cutaneous T-cell lymphoma," Histopathology, vol. 53, no. 3, pp. 267-277, 2008.

[150] L. Ellis, Y. Pan, G. K. Smyth et al., "Histone deacetylase inhibitor panobinostat induces clinical responses with associated alterations in gene expression profiles in cutaneous Tcell lymphoma," Clinical Cancer Research, vol. 14, no. 14, pp. 4500-4510, 2008.

[151] R. K. Lindemann, A. Newbold, K. F. Whitecross et al., "Analysis of the apoptotic and therapeutic activities of histone deacetylase inhibitors by using a mouse model of B cell lymphoma," Proceedings of the National Academy of Sciences of the United States of America, vol. 104, no. 19, pp. 8071-8076, 2007.

[152] M. T. Epping, L. Wang, J. A. Plumb et al., "A functional genetic screen identifies retinoic acid signaling as a target of histone deacetylase inhibitors," Proceedings of the National Academy of Sciences of the United States of America, vol. 104, no. 45, pp. 17777-17782, 2007.

[153] W. Fiskus, R. Rao, P. Fernandez et al., "Molecular and biologic characterization and drug sensitivity of pan-histone deacetylase inhibitor resistant acute myeloid leukemia cells," Blood, vol. 112, no. 7, pp. 2896-2905, 2008.

[154] V. R. Fantin, A. Loboda, C. P. Paweletz et al., "Constitutive activation of signal transducers and activators of transcription predicts vorinostat resistance in cutaneous Tcell lymphoma," Cancer Research, vol. 68, no. 10, pp. 37853794, 2008. 

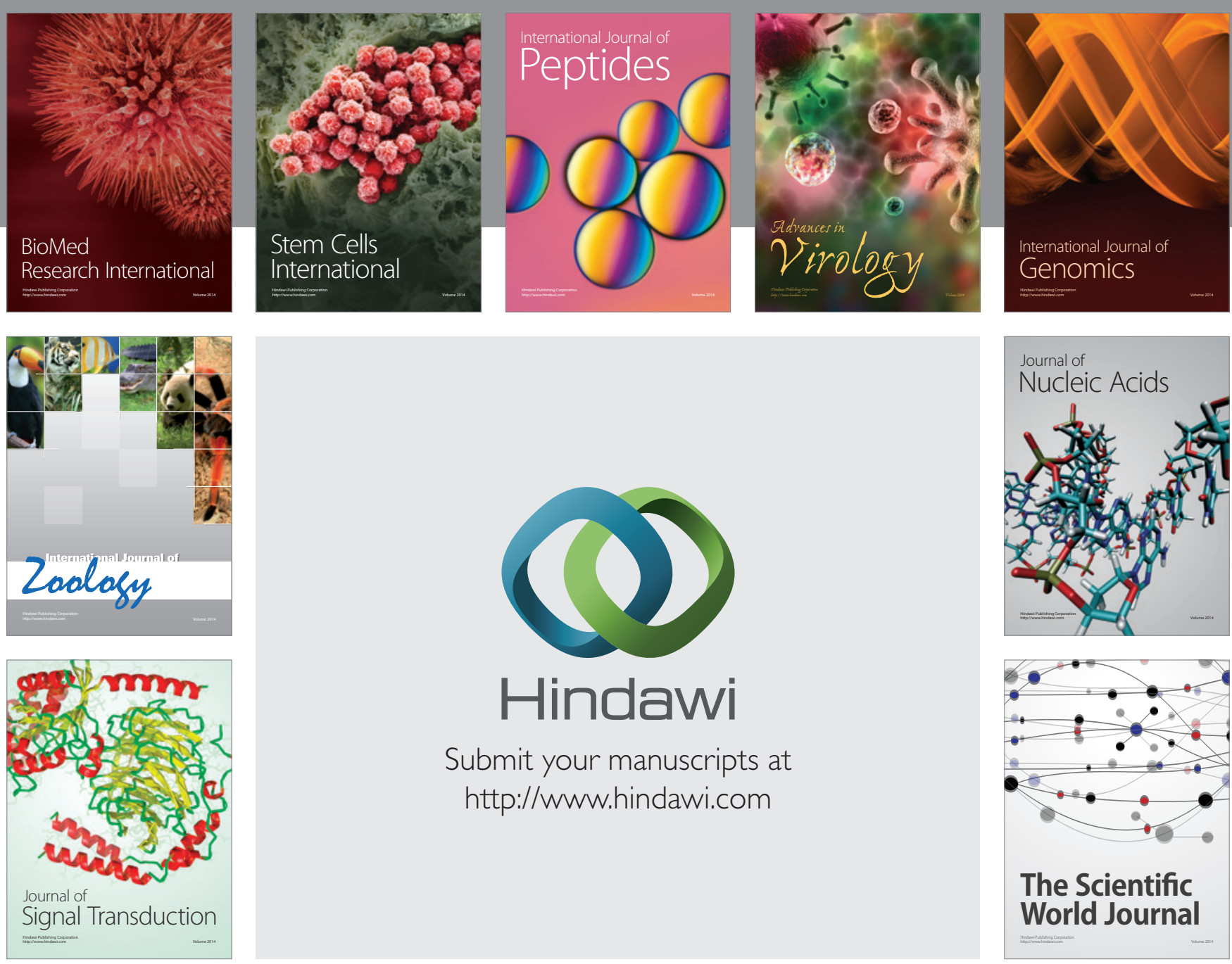

Submit your manuscripts at

http://www.hindawi.com
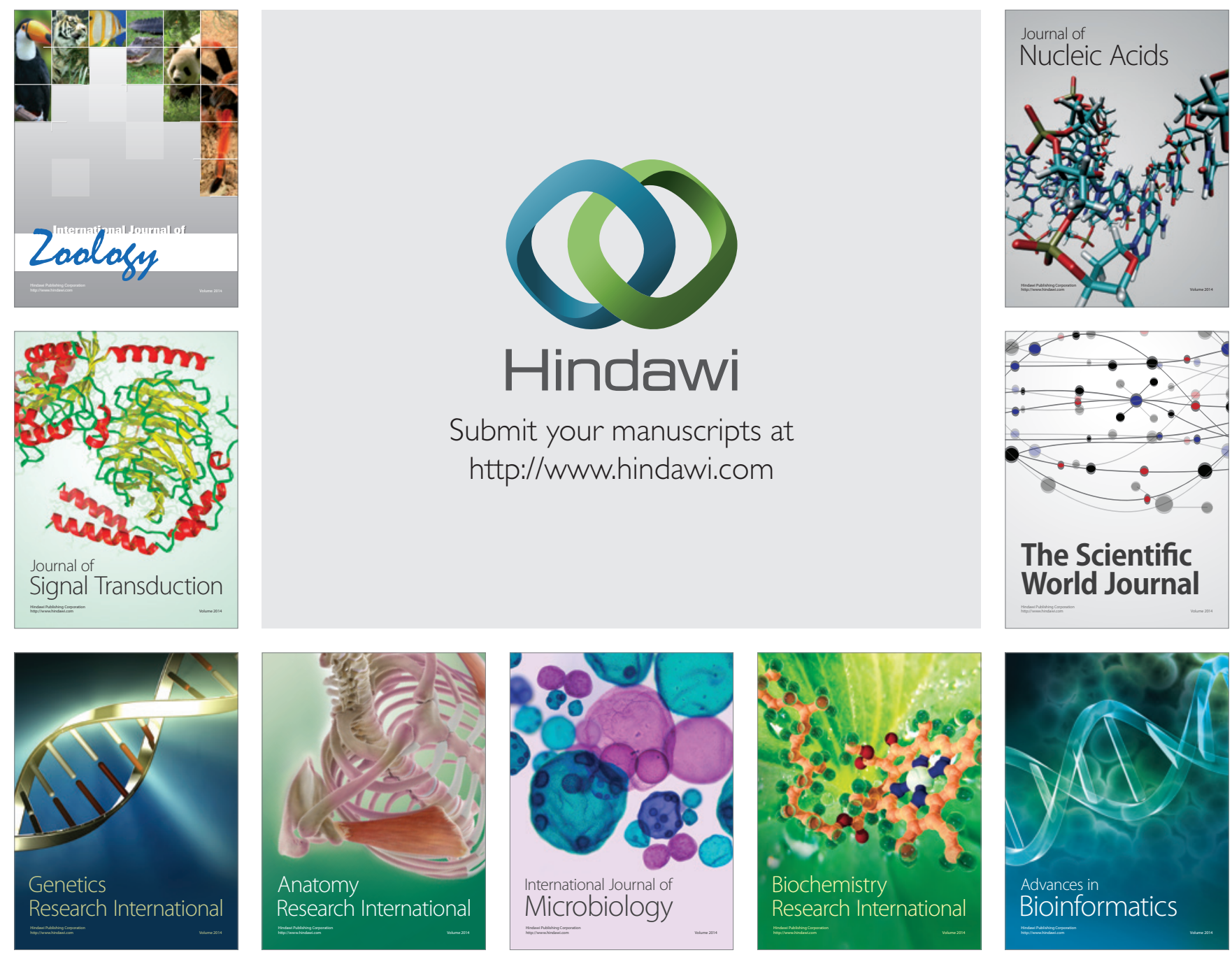

The Scientific World Journal
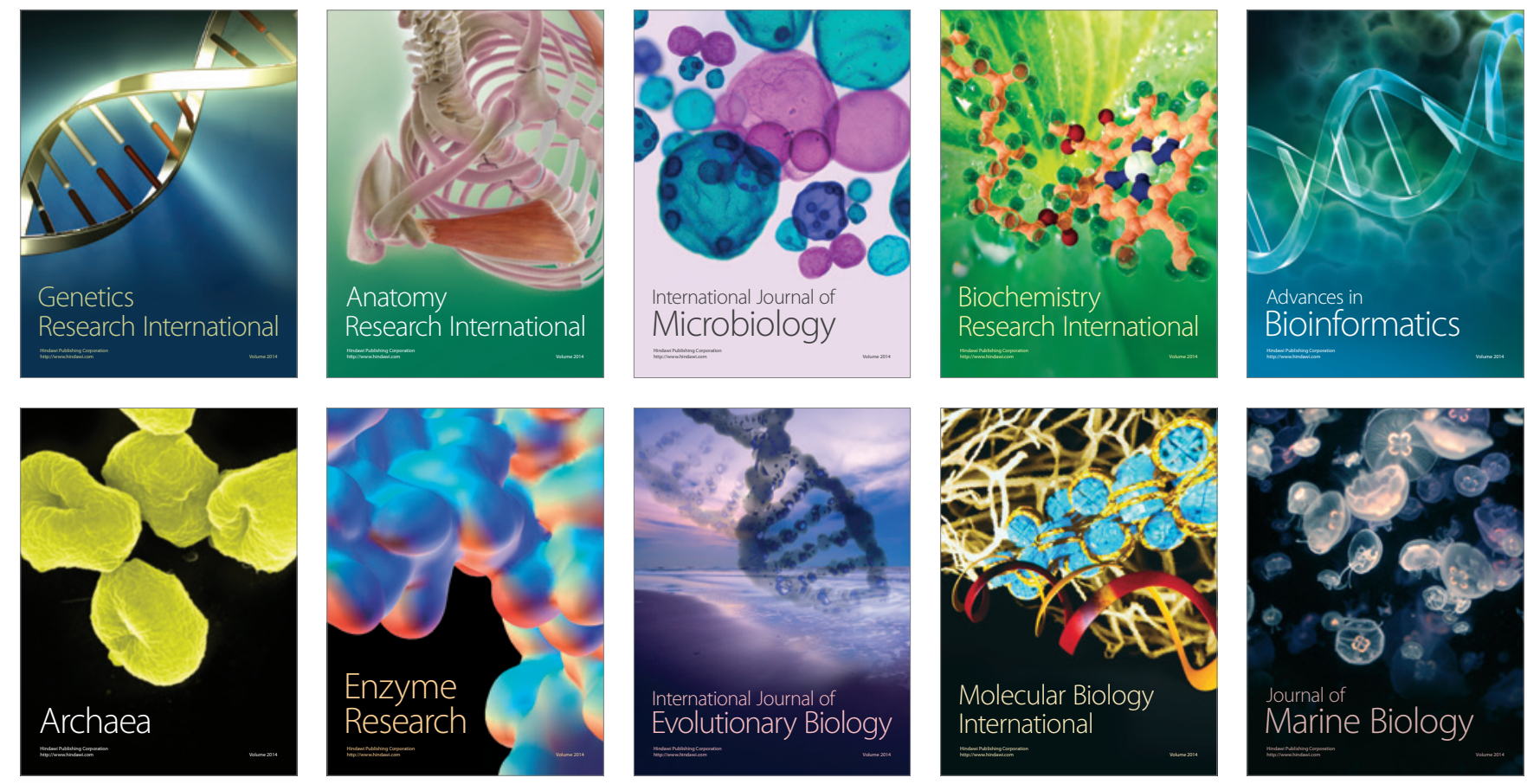